NBER WORKING PAPER SERIES

\title{
ELITE COLLEGES AND UPWARD MOBILITY TO TOP JOBS AND TOP INCOMES
}

\author{
Seth D. Zimmerman \\ Working Paper 22900 \\ http://www.nber.org/papers/w22900 \\ NATIONAL BUREAU OF ECONOMIC RESEARCH \\ 1050 Massachusetts Avenue \\ Cambridge, MA 02138 \\ December 2016, Revised September 2018
}

This paper was previously circulated under the title 'Making the One Percent: The Role of Elite Universities and Elite Peers.' I thank Joseph Altonji, Marianne Bertrand, Eduardo Engel, Francisco Gallego, Martin Hackmann, Lisa Kahn, Adam Kapor, Amanda Kowalski, Fabian Lange, Costas Meghir, Craig Palsson, Jamin Speer, Ebonya Washington, and numerous seminar participants for valuable comments. I thank Justine Hastings and Christopher Neilson for detailed discussions and for their collaboration in developing the datasets used for this project. I thank Cristobal Huneeus and Federico Huneeus for valuable comments and for support in data access. I thank DEMRE Directors Ivan Silva and Eduardo Rodriguez for access to college application data. I thank Pablo Maino, Valeria Maino, and Nadia Vazquez for assistance with archival research. I thank SII staff for their support in access to tax records. I thank Anely Ramirez for her invaluable contributions to data collection and institutional research. I thank Sean Hyland and Raimundo Smith for excellent research assistance. I thank the Yale Program in Applied Economics and Policy, the Cowles Structural Microeconomics Program, and the University of Chicago Booth School of Business for financial support. All errors are my own. Required disclosure: Information contained herein comes from taxpayers' records obtained by the Chilean Internal Revenue Service (Servicio de Impuestos Internos), which was collected for tax purposes. Let the record state that the Internal Revenue Service assumes no responsibility or guarantee of any kind for the use or application made of the aforementioned information, especially in regard to the accuracy, currency, or integrity. The views expressed herein are those of the author and do not necessarily reflect the views of the National Bureau of Economic Research.

NBER working papers are circulated for discussion and comment purposes. They have not been peer-reviewed or been subject to the review by the NBER Board of Directors that accompanies official NBER publications.

(C) 2016 by Seth D. Zimmerman. All rights reserved. Short sections of text, not to exceed two paragraphs, may be quoted without explicit permission provided that full credit, including () notice, is given to the source. 
Elite Colleges and Upward Mobility to Top Jobs and Top Incomes

Seth D. Zimmerman

NBER Working Paper No. 22900

December 2016, Revised September 2018

JEL No. I24,I26

\begin{abstract}
This paper asks whether elite colleges help students outside of historically advantaged groups reach top positions in the economy. I combine administrative data on income and leadership teams at publicly traded firms with a regression discontinuity design based on admissions rules at elite business-focused degree programs in Chile. The $1.8 \%$ of college students admitted to these programs account for $41 \%$ of leadership positions and $39 \%$ of top $0.1 \%$ incomes. Admission raises the number of leadership positions students hold by $44 \%$ and their probability of attaining a top $0.1 \%$ income by $51 \%$. However, these gains are driven by male applicants from high-tuition private high schools, with zero effects for female students or students from other school types with similar admissions test scores. Admissions effects are equal to $38 \%$ of the gap in rates of top attainment by gender and $54 \%$ of the gap by high school background for male students. A difference-in-differences analysis of the rates at which pairs of students lead the same firms suggests that peer ties formed between college classmates from similar backgrounds may play an important role in driving the observed effects.
\end{abstract}

Seth D. Zimmerman

Booth School of Business

University of Chicago

5807 S. Woodlawn Avenue

Chicago, IL 60637

and NBER

seth.zimmerman@chicagobooth.edu

An online appendix is available at http://www.nber.org/data-appendix/w22900/Zimmerman_Top_Jobs_appendix.pdf 


\section{Introduction}

This paper asks whether elite colleges help students outside of historically advantaged groups reach top positions in the economy. What determines upward mobility into top jobs and top incomes is the subject of a longstanding debate, the stakes of which have grown over time as top income shares have risen. ${ }^{1}$ Elite universities are an important causal channel to explore because their graduates hold large shares of top positions. For example, Capelli and Hamori (2004) report that $10 \%$ of Fortune 100 executives in 2001 attended an Ivy League college, while Cohen et al. (2008) find that $10 \%$ of publicly traded firms in the US have at least one senior manager from Harvard. What happens at elite universities may affect not just access to top jobs for individual students, but the composition of top positions overall. Further, helping talented students access economic opportunity regardless of background is a core policy objective for colleges in general and elite universities in particular (Hoxby and Avery 2013, Chetty et al. 2017).

In this paper, I combine administrative and archival data from Chile with a regression discontinuity design to study how admission to elite business-focused degree programs affects the rates at which students from different backgrounds reach top positions in the economy. I link data on applications to elite degree programs dating back more than 40 years to administrative tax records as well as to records of top management teams at publicly traded corporations, and use variation in admissions outcomes generated by score-based cutoff rules to identify the causal effects of admission. In addition to facilitating measurement of top outcomes and credible causal inference, the Chilean setting is an informative one because intergenerational income elasticities, top income shares, and measures of business transparency suggest opportunities for upward mobility similar to those in many Latin American and EU member states. ${ }^{2}$

I have three findings. First, a small number of highly selective, business-focused degree programs account for large shares of leadership positions and top incomes. Second, gaining admission to one of these programs rather than a less selective program raises mean income and rates of top attainment for male students from wealthy backgrounds, but not for other students. Admission thus widens gaps in top attainment by gender and baseline socioeconomic status (SES). Third, elevated returns for high-SES men are hard to explain with differences in baseline skills, propensity to work in high-paying industries, or college completion rates. However, college classmates from wealthy backgrounds are more likely to lead the same firms than comparable pairs of non-peers or classmates from low-SES backgrounds. Peer ties formed between high-SES classmates may be one mechanism through which elite universities raise top attainment.

\footnotetext{
${ }^{1}$ See, e.g., Miller (1949), Miller (1950), Urahn et al. (2012), or Rivera (2016) for a discussion of mobility to top positions, and Atkinson et al. (2011) or Alvaredo et al. (2013) for trends in top income shares.

${ }^{2}$ Nor are they obviously worse than in the US. See Section 2 for details.
} 
The analysis proceeds in three steps. I first present new descriptive evidence on the distribution of firm leadership and top income attainment by educational background and student characteristics. I use data on the population of college-bound high-school graduates ${ }^{3}$ from 1980 through 2001, and focus on two measures of top attainment: holding an executive management position or board seat at a publicly traded firm, or having an income in the top $0.1 \%$ of the observed income distribution. I measure these outcomes for students who are between 12 and 39 years removed from the year of college application, or roughly ages 30 through 57 . This allows time for students to complete schooling and reach their career peaks.

I find that the $1.8 \%$ of students admitted to three business-focused majors at the two most selective universities in Chile (henceforth 'elite degree programs') make up $41 \%$ of all directors and top managers, 27\% of the top 1\% of the income distribution between 2005 and 2013, 39\% of the top $0.1 \%$, and $45 \%$ of the top $0.01 \%$. The gap between rates of leadership attainment at these elite degree programs and the average program is roughly similar to the gap observed in the US between Ivy League graduates and the average college graduate. Conditional on selectivity, major matters: students in top business-focused programs are 16.6 times more likely to have an income within the top $0.1 \%$ of the distribution than students in equally selective medical programs, where average incomes are also high. For students at elite degree programs, gender and family background are critical determinants of top attainment. Taking attendance at a hightuition private high school as a proxy for parental SES, I find that compared to male students from other backgrounds (female students), high-SES male students hold 3.4 (6.7) times more leadership positions and are 4.2 (11.4) times more likely to have top $0.1 \%$ incomes.

The second stage of the analysis uses a regression discontinuity design based on admissions cutoffs to measure the causal effects of elite degree programs on the rate at which students reach top positions. Students crossing the threshold for admission to elite degree programs are most often drawn from less selective programs in similar fields. This means that effects can be interpreted in terms of changing selectivity within career path, rather than, for example, switches from medical to business careers within top universities.

Admission to an elite degree program raises the number of leadership positions students hold by $44 \%$ and the probability of attaining an income in the top $0.1 \%$ of the distribution by $51 \%$ relative to the below-threshold mean. However, gains accrue only to male applicants from private high schools, for whom rates of leadership (top income) attainment rise by $54 \%$ (69\%). Effects for women and male students not from private high schools are small and statistically indistinguishable from zero. The difference between the effect of admission for male vs. female students is equal to $36 \%$ of the gender gap in top income attainment for students at top programs. The

\footnotetext{
${ }^{3}$ Specifically, the population of students who take a required college admissions exam.
} 
difference in admissions effects by high school type for male students is equal to $54 \%$ of the cross-group gap.

These findings confirm that the correlation between elite college background and the attainment of top outcomes or leadership positions documented in previous studies in part reflects an underlying causal relationship (Sorokin 1925, Taussig and Joslyn 1932, Miller 1949, Miller 1950, Warner and Abegglen 1955, Useem and Karabel 1986, Temin 1997, Temin 1999, Cappelli and Hamori 2004). They are consistent with descriptive findings from Chetty et al. (2017) that a small number of top colleges account for a large share of upper tail incomes, and with additional calculations using Mobility Report Card data showing that there is a steep SES gradient in upper tail attainment within these colleges. They are also consistent with descriptive findings from Bertrand et al. (2010) that male graduates from top US MBA programs experience greater labor market success than female graduates. They contrast with causal evidence that access to higher education in general and more selective higher education in particular flattens SES gradients in income at lower points in the selectivity and income distributions (Zimmerman 2014, Dale and Krueger 2014). I find no evidence of mismatch: admission to elite business programs does not lead to poorer long-run outcomes for low-SES individuals (Sander 2004, Rothstein and Yoon 2008, Arcidiacono and Lovenheim 2016, Dillon and Smith 2017).

The remainder of the paper asks why elite business degrees only raise rates of top attainment for male students from wealthy backgrounds. Features of the data are inconsistent with several plausible channels. I first show that returns to admission for female students and male students from less wealthy backgrounds are zero across the income distribution, not just at the top. It is not the case that these students realize gains but start at base levels too low to reach the top of the distribution. The elite degrees that offer a path to the top for male students from private high school backgrounds improve labor market outcomes only for this group. Second, I show that top attainment effects for private high school men cannot be explained by differential returns to correlates such as admissions test scores or geography. Third, I show that differential effects appear to be driven by changes in success within business-focused careers, not differences in career aims. Regardless of family background, applicants to elite degree programs most often go on to work in business-oriented sectors like finance and trade. Analyses that condition on students' listed next choices confirm that changes in selectivity play a key role in driving differential labor market outcomes holding other degree attributes fixed.

Fourth, I show that differential admissions effects by high school type and gender are not features of all high-earning career paths in Chile, and cannot easily be attributed to cross-group differences in academic achievement. I illustrate this through a comparison to selective medical degree programs, where average earnings and selectivity are comparable to the best business 
programs but top outcomes are rare. Women and low-SES men realize large returns from elite medical admission. Though admission to these programs does not affect rates at which students reach incomes within the top $0.1 \%$, it eliminates the SES gradient in rates of attainment of top $10 \%$ incomes and reduces the gender gap as well. These findings complement research showing that business programs stand out from programs in other fields in that they raise earnings more on average for students from richer families (Hastings, Neilson, and Zimmerman 2013; henceforth HNZ). In both business and medical programs, women complete at higher rates than men, and private school students at higher rates than other students. Differences in educational attainment thus fail to explain differential returns within business programs (women are more likely to graduate than men, but have lower returns) or across program types (differences in completion rates have the same signs across program types, while differences in returns have opposite signs). This suggests that the mechanisms driving the high returns for high-SES male students in business programs have more to do with labor market institutions in the business career track than with the Chilean economy in general or the academic content of business programs.

Why are business careers different? One mechanism that may be important is peer relationships. Descriptive accounts of business programs often discuss the importance of peer ties, in particular peer ties formed between students from similar backgrounds, as drivers of success (Mills 1956, Kantor 2013), ${ }^{4}$ and institutions themselves highlight peer networking opportunities in promotional materials (University of Chicago Booth 2014, Harvard Business School 2013).

The third stage of analysis investigates the role of peer ties as determinants of leadership outcomes. I use a difference-in-differences approach that compares the rates at which pairs of college classmates who attend the same degree program at the same time serve on management teams at the same firm to rates for pairs of students who attend the same degree program at different times or different degree programs at the same time. The intuition is that within a degree program, classmates in the same cohort are similar to pairs of students a few years apart in terms of pre-college backgrounds and institutional inputs, but are more likely to know each other and to have mutual contacts. The use of data on pairs of individuals to identify peer ties resembles Bayer, Ross, and Topa (2008), who use pairs data to study neighborhood effects.

I find that admission to an elite degree program increases the rate at which male students from private high schools lead the same firms as college classmates also from private high school backgrounds, but does not alter their chances of leading the same firms as non-classmates or classmates from different backgrounds. This suggests that peer effects play a role in determining leadership attainment, and is difficult to reconcile with explanations based on general or

\footnotetext{
${ }^{4}$ Kantor (2013) describes a student at Harvard Business School who 'was told by her classmates that she needed to spend more money to fully participate, and that the difference between a good experience and a great experience is only $\$ 20,000 . "$
} 
firm-specific skill accumulation. That students form ties with peers from similar backgrounds is consistent with descriptions of peer group formation among college students in Marmaros and Sacerdote (2006) and Mayer and Puller (2008), and can help explain the finding of large gains in top outcomes for students from wealthy backgrounds and zero gains for other students. These results suggest that the peer relationships shown in previous studies to affect managerial behavior conditional on attaining a top position (Shue 2013, Fracassi and Tate 2012, Fracassi 2016) also affect rates at which students obtain management positions. I extend research showing that college ties affect early-career outcomes (Marmaros and Sacerdote 2002, Arcidiacono and Nicholson 2005) to high levels of occupational attainment. ${ }^{5}$

My findings on the role of elite universities in providing a pathway to top positions and the importance of peer effects as an underlying mechanism build on an extensive literature studying the effects of college selectivity on mean earnings. Dale and Krueger (2002), Black and Smith (2004), Black and Smith (2006), Hoekstra (2009), Saavedra (2009), and Öckert (2010) each provide evidence on the mean returns to increasing college selectivity. ${ }^{6}$ The most closely related paper within this literature is HNZ, which uses discontinuous admissions rules in the population of Chilean degree programs to study the effects of admission to different kinds of degrees. HNZ develops a model of earnings determination and selection into degree programs, and identifies the model using variation generated by admissions discontinuities. The authors find that increasing selectivity raises mean earnings within some fields, including business, and also show that transitions from low- to high-earning fields lead to earnings gains. The contribution of the present paper is to describe the special role of elite business programs in producing a large share of corporate leaders and top incomes, to show evidence that these programs widen gaps in top attainment by gender and SES, and to present suggestive evidence that peer ties are a mechanism in producing these outcomes.

\section{Institutional background and data collection}

\subsection{Inequality and mobility in international context}

Chile is a middle-income OECD member country, with per capita GDP equal to about $\$ 22,000$ after adjusting for purchasing power parity (values reported in constant 2014 USD except as

\footnotetext{
${ }^{5}$ de Giorgi et al. (2010), Sacerdote (2001) and Oyer and Schaefer (2012) also study the role of peers in career choices.

${ }^{6}$ In addition, Kaufmann et al. (2013) show that increasing selectivity may also have returns through the marriage market. Oyer and Schaefer (2009) and Arcidiacono et al. (2008) study applicants to law and business graduate programs, respectively, and find evidence of large earnings returns. Reyes et al. (2016) model selection into college for Chilean students and find evidence of positive but heterogeneous returns.
} 
noted). This is the highest in Latin America and roughly comparable to Eastern European states such as Poland (World Bank 2016). As is true elsewhere in Latin America, inequality in Chile is high. Fairfield and Jorratt De Luis (2015) report estimates of top 1\% income shares obtained from administrative tax records in 2005 that range from 15\% to $23 \%$. For comparison, similarly measured top $1 \%$ shares were $18 \%$ in the US, $20 \%$ in Colombia, and $22 \%$ in Argentina. ${ }^{7}$

Despite high levels of income inequality, rates of intergenerational mobility for the primarily urban population that applies to and attends the elite programs that are the focus of this study are comparable to those observed in many developed countries. $41 \%$ of Chileans and $78 \%$ of elite applicants live in the greater Santiago area. ${ }^{8}$ Both elite universities are located in Santiago. Rates of income mobility in this region are similar to those observed in the US or UK in methodologically comparable studies. Núñez and Miranda (2011) use an instrumental variables approach to estimate the intergenerational income elasticity (IGE) in greater Santiago at 0.52 to 0.54. Solon (1992) and Björklund and Jäntti (1997) conduct comparable exercises in US data, and obtain estimates of roughly 0.5, while Dearden et al. (1997) find a value of 0.57 in the UK. ${ }^{9}$

Chile has rates of educational attainment that are similar to the US, and low levels of public corruption. 38\% of adults between 25 and 34 years old in 2010 had obtained a tertiary degree, compared to $42 \%$ in the US, $22 \%$ in Mexico, and 12\% in Brazil (OECD 2012). Only 0.7\% of businesses report 'informal payments' to government officials, compared to $18.1 \%$ in Argentina, $11.7 \%$ in Mexico, or $14.7 \%$ in Poland. See Table A-1 for a comparison of economic and business indicators in Chile to those for several other countries.

To summarize, the subjects of this study work in an economy with levels of inequality and rates of mobility similar to those observed in the US. Comparisons between Chile and Latin American countries like Colombia or Argentina seem reasonable. Comparisons to larger, higher-income countries like the US are less straightforward, but it is not obvious that urban Chileans face a more challenging environment for upward mobility than prevails in the US.

\footnotetext{
${ }^{7}$ These shares exclude accrued profits and capital gains to facilitate cross-national comparisons. The Argentina share is from 2004 and adjusts for evasion; the Colombia share is from 2003. See Fairfield and Jorratt De Luis (2015).

${ }^{8}$ Population statistics from 2014. Elite applicant statistics from the regression discontinuity sample, see Table 6.

${ }^{9}$ US IGE values in the neighborhood of 0.5 are larger than those reported in, e.g., Lee and Solon (2009), where estimates take an average value of 0.44 across all cohorts. However, as Chetty et al. (2014) point out, IGE estimates are sensitive to methodological choices. Núñez and Miranda (2011) use a two-sample two-stage least squares approach that instruments for father's income using schooling and occupation. Solon (1992) shows that this approach can upwardly bias IGE estimates relative to alternative approaches, so it is important to contrast Núñez and Miranda (2011) with IV estimates from other countries. The findings from Solon (1992), Björklund and Jäntti (1997), and Dearden et al. (1997) cited here all instrument for father's income as in Núñez and Miranda (2011).
} 


\subsection{Higher education institutions and applications}

Until the late 1990s, almost all college students in Chile attended one of 25 'traditional' universities (Rolando et al. 2010). These are known as CRUCH universities (an acronym for 'Council of Rectors of Universities of Chile') and include a mix of public and private institutions. The two most selective are the Universidad de Chile (UC) and Pontificia Universidad Católica de Chile (PUC). Both are world class institutions, ranking 13th and 7th, respectively, in the 2016 U.S. News Latin American university rankings (US News and World Report 2016). Within these institutions, some fields are more selective than others. I focus much of my analysis on three highly selective, business-oriented fields of study: law, business, and an applied math degree known as 'Civil Engineering, Common Plan.' ${ }^{10}$ I show in Section 3 that students admitted to these programs account for large shares of leadership positions and top incomes. These findings are consistent with reports from corporate recruiters (Seminarium Penrhyn International 2003).

CRUCH applicants commit to specific fields of study prior to matriculation. Following their final year of high school, students take a standardized admissions exam. ${ }^{11}$ After receiving the results from this test, students apply to up to eight degree programs by sending a ranked list to a centralized application authority. Degree programs consist of institution-degree pairs; e.g., business at PUC. Degree programs then rank students using an index of admissions test outcomes and grades, and students are allocated to degrees using a deferred acceptance algorithm. Students are admitted to only the most preferred degree program for which they have qualifying rank. A student who is rejected from his first choice but admitted to his second choice will not be considered for admission at his third choice. Students near the cutoff for admission are placed on a waitlist, and both admissions and waitlist outcomes are published in the newspaper. The regression discontinuity analysis compares the students near the bottom of the published admissions lists to students near the top of the waitlists. ${ }^{12}$

Four features of this process are worth highlighting. First, students do not have access to ex post choice between accepted outcomes. To change institution-degree enrollment, they must wait a year and retake the admissions test. Second, the scores required for admission vary from year to year depending on demand for and the number of spots universities allocate to each career. Students' inability to precisely predict cutoff scores is consistent with the imprecise control condition required for unbiased regression discontinuity estimation (Lee and Lemieux 2010). Third,

\footnotetext{
${ }^{10}$ Many Chilean degree programs that do not resemble engineering to US observers have the word 'engineering' in the title (e.g., business degrees are titled 'Commercial Engineering'). The engineering program I consider here produces many business leaders and is best thought of as a business-oriented applied math degree.

${ }^{11}$ Before 2003, the Prueba de Aptitud Académica (PAA); after 2003, the the Prueba de Selección Universitaria (PSU).

${ }^{12}$ Weights may differ by degree program, so this mechanism is not a serial dictatorship. One implication is that the approach to RD estimation in Abdulkadiroglu et al. (2017) does not apply directly.
} 
elite programs typically admit more students than their target class size. This allows some students to turn down spots (e.g., for medical reasons) without waitlist movement, and means that admissions cutoffs observed in the newspaper will bind. See Online Appendix B.1 for more details. Fourth, students enrolled in different degree programs at the same institution generally do not take courses together. Each program studied here has its own physical plant. For this reason, I think of peer effects as operating within degree programs, not institutions.

\subsection{Secondary education institutions}

The effects of elite admission may depend on students' family background. In the absence of data on parental income or education, I use high school type to divide students into coarse socioeconomic strata. I interpret high school type as a proxy for home, school, and community inputs. I leave for future work questions related to the causal effect of high school background on labor market outcomes, holding other inputs fixed.

I focus on two types of high schools: private high schools and non-private high schools. The private high school category consists of what Hsieh and Urquiola (2006) refer to as 'unsubsidized' private schools: private institutions that do not receive public funding. They generally charge high tuition and serve upper-income households. The non-private category includes both municipal schools, which are locally-run schools similar to public schools in the US, and voucher schools, which may be run by private groups but receive public funding and do not charge tuition (Neilson 2013). Unsubsidized private high schools accounted for less than ten percent of high school enrollment in the 1980s and early 1990s (Hsieh and Urquiola 2006). Online Appendix B.2 describes the classification of high school types.

\subsection{Data collection}

\subsubsection{Application records}

I use three types of data on the college application process. The first is data on all admissions test takers between 1980 and 2001. The second is data on admissions outcomes at all CRUCH degree programs for the years 1982 through 2001. Applicants are a subset of test takers. The third is data on admissions outcomes at elite law, engineering and business programs for the years 1974 through 2001. This means that by 2013 (the last year for which I observe outcome data), the oldest students in the application dataset are 39 years removed from college application, or roughly 57

years old. Applications data are digitized from hard copies of published application and waitlist 
announcements stored in the Biblioteca Nacional de Chile. Records include all admitted students as well as a list of marginal rejected students that is typically equal in length to the list of admits. Data on student preference rankings becomes available beginning in 2000. I discuss this data in section 5.3.2.

Administrative application records include high school identifiers. However, these identifiers vary across years, and mappings between identifiers and school names are not available in all years. To identify high school types, I use students who apply to college in multiple years to link codes across years. I then use data on school type from 2000 to classify schools from earlier cohorts. This procedure will work if there are at least some multi-year applicants in each high school in each year and the set of high schools is stable over time. I match 79 percent of elite admissions between 1980 and 2001 (the years used for descriptive analysis of income data) and 60 percent of elite applications between 1974 and 1991 (the years used in the discontinuity analysis of leadership). Miscategorization of high school types will bias estimates of differences between private and public high schools towards zero.

The link between application records outcome records relies on government-issued personal identifiers (known as the Rol Único Tributarios; abbreviated as RUTs). I match 94\% of applications over the 1974-2001 period to RUTs. Non-matches are due to illegible records in newspaper or archival data. My discussion in the main text focuses on applications that are successfully matched to RUTs. See Online Appendix B.1 for a discussion of the match process and evidence that match rates are balanced across the admissions threshold.

\subsubsection{Firm leadership records}

Publicly traded companies in Chile are required to disclose the identities of top executives and board members to the Superintendicia de Valores y Seguros (SVS), the Chilean analogue to the Securities and Exchange Commission in the US. I obtain leadership data using a web scrape of the SVS website (SVS 2013). I conducted this scrape in March of 2013. The SVS website allows users to search historical filing records by date for each firm. I searched for all executive managers and directors who served between January 1st, 1975 and January 1st 2013. Most firms do not provide leadership records for the earlier part of this period. The median leader was hired in 2009, and 92 percent of leaders were hired in 1998 or later. 47\% of leaders list a departure date, and the median year of departure for those who do is 2011. These data are therefore best viewed as a snapshot of leadership teams in the 2010s.

I observe a total of 10,220 leadership positions, of which 2,522 are held by applicants to elite degree programs in 1974 or later. Of the 2,522, 1,543 are directorships and the remainder are C- 
suite roles. Applicants hold these positions at a total of 619 firms; there are many firms in which more than one applicant holds a top job. The firms in this data span a wide variety of sectors and corporate parents, and including some of the largest companies in the world and Latin American subsidiaries of US companies. See Online Appendix B.3 for details.

\subsubsection{Tax records}

I match admissions test takers in the years 1980 and later to individual tax records at the Chilean tax authority in compliance with Chilean privacy laws. Because test-taking is a requirement for application, the group of admissions test takers includes all applicants to elite programs. Following procedures developed by the Chilean tax authority and the World Bank (Cossio and Andres 2016), I construct individual income measures that include labor earnings (reported to the tax authority by employers) as well as income from pensions, rents, taxable capital gains, dividends, and distributed profits. Income data are not topcoded. My income measure omits business profits that are reinvested in firms, which may lead to underestimates of top income shares (Fairfield and Jorratt de Luis 2015). For workers employed in long-term contracts, records also contain basic employer characteristics such as sector. Data are available on an annual basis for the years 2005 through 2013. See Online Appendix B.4 for details.

Using these records I construct a dataset of labor force participants that excludes individuals who are fewer than 12 years removed from the year of college application (roughly age 30). The primary dependent variable of interest in the income data is an indicator for presence in the top $0.1 \%$ of the year-specific income distribution. I compute percentile values within the sample of labor force participants, defined to include all individuals who have total annual income below $50 \%$ of what one would earn from a full year's work at the monthly minimum wage (about USD \$2,300 per year in 2014 dollars). In 2013, the threshold for a top $0.1 \%$ income was roughly $\$ 330,000$, and average income in the top $0.1 \%$ was about $\$ 530,000$. Average income in the top $0.01 \%$ was about $\$ 1.3$ million. In the regression discontinuity analysis, individuals with incomes below the cutoff for the labor force participant sample are coded as not having top incomes.

\section{Which degree programs lead to top outcomes?}

The business, law, and engineering programs at UC and PUC stand out relative to programs in other fields and other programs in the same field for the high rates at which their students attain top positions in management and in the income distribution. Figure 1 presents descriptive statistics comparing these programs to other degrees. Panel A plots mean income for students 
admitted to each degree program in the admitted student sample on the vertical axis against the mean of math and reading test scores on the horizontal axis. Degrees in the three businessfocused fields are denoted by markers of different shapes. The UC and PUC programs in these fields have solid fill, while non-elite programs in the same fields have hollow fill. Medical programs are denoted by hollow circles.

Two features of this figure are worth highlighting. First, business-focused degrees have high average earnings relative to other programs at similar selectivity levels. Second, the business, engineering, and law programs at UC and PUC are the most selective and have the highest average earnings within their respective fields. Mean income and selectivity at these programs are among the highest at any program and similar to levels observed at programs that train medical doctors. Table 1 reports descriptive statistics that accompany this and subsequent panels of Figure 1. Mean income for students admitted to elite degree programs in my data is just under $\$ 74,000$. Average math and reading test scores for elite admits are roughly 100 points above the average for all admitted students, and 200 points above the average for all test takers. ${ }^{13}$

Though both elite business-focused programs and medical programs have high mean incomes, the distribution of income within these programs is very different. Panel B of Figure 1 plots the density of income by percentile of the test-taker income distribution for students admitted to the business-focused programs at PUC and UC and for students admitted to the medical programs at the same universities. Densities for both degree types are low below the 95th percentile. Medical admits are more likely to have incomes between the 95th and 98.5th percentiles than business admits. Above the 99th percentile, the density of the income distribution for medical admits falls, while the density for business admits rises. Elite business admits have incomes in the top $0.1 \%$ of the distribution in $1.6 \%$ of of earnings years, compared to $0.1 \%$ for medical admits. The business admits make up $1.8 \%$ of admissions test takers, but account for $27 \%$ of the top $1 \%$ of the distribution, $39 \%$ of the top $0.1 \%$, and $45 \%$ of the top $0.01 \%$.

Patterns in leadership attainment are similar to those for top income. Panel C of Figure 1 plots the mean number of leadership positions held for admitted students at each program against program selectivity. Six of the top nine programs in terms of leadership production are in the elite, business-focused set, including the top four. Students admitted to elite programs attain top positions at a rate of 4.1 per one hundred students, compared to 0.2 per one hundred students in the applicant population. The $1.8 \%$ of admissions test takers from elite business programs hold $41 \%$ of the leadership positions. Leadership rates are close to zero for medical programs. The concentration of top attainment within a small number of programs motivates an investigation

\footnotetext{
${ }^{13}$ The standardized admissions exam is normed to have a mean of 500 and a standard deviation of 100 across all test takers in each subject in each year. Some students take the exam in multiple years, and in this table I report scores for the first time students take the exam. First-time takers score somewhat lower than test takers as a whole.
} 
of their causal effects.

The gap between rates of leadership and top income attainment at elite programs and the average program is roughly similar to the gap between Ivy League institutions and other institutions observed in the US. A simple back of the envelope calculation indicates that Ivy League graduates held between 6 and 10 times as many Fortune 100 executive positions as the average four-year college graduate in 2001, and between 8 and 12 times as many positions in $1980 .{ }^{14}$ In Chile, students admitted to one of the six elite degree programs hold 4.1 positions per 100 students, compared to 0.4 positions per 100 students in the population of students admitted to some degree program- about 10 times more positions. Similarly, students enrolling in Ivy League institutions are 7.8 times more likely to have incomes within the top $1 \%$ of distribution for their age cohort than a students in the sample of four-year college enrollees. ${ }^{15}$ In Chile, students in the six elite degree programs are 6.1 times more likely to reach a top $1 \%$ income than the average admitted student.

Within the elite business-focused degree programs, male students from private high schools are more likely to obtain top positions than other students. Panel D of Figure 1 shows the density of the income distribution for elite business admits split by gender and, within male students, by high school type. Above the 99.5th percentile of the distribution, the density for male students from private high school backgrounds rises sharply. There is no similar uptick in the density for female students or other male students. Male students from private high schools are 4.2 (11.4) times as likely to have an income in the top $0.1 \%$ as male students from other high schools (female students). Similarly, male students from private high schools hold 6.8 leadership positions per hundred students, compared to 2.0 positions per hundred for students not non-private high school men and 1.0 for women.

Within-institution SES gradients are hard to compare quantitatively across countries without comparable parental background measures. But qualitative relationships are again similar to those in the US. Ivy League students with parents in the top quintile of the income distribution are $65 \%$ more likely to have within-cohort top $1 \%$ incomes than those with parents in the bottom income quintile of the distribution. In Chile, private high school students (either male or female) are $123 \%$ more likely to reach a top $1 \%$ income than other students at top programs.

\footnotetext{
${ }^{14}$ The calculation works as follows. Capelli and Hamori (2004) report that $10 \%$ (14\%) of Fortune 100 executive managers in 2001 (1980) were Ivy League graduates. Ivy League graduates accounted for 1.1\% of bachelor's degree recipients and $1.8 \%$ of degree recipients at the bachelor's level or above in 1980, the earliest year for which data are available. (Source: author's calculations from IPEDS.) If we assume Ivy League graduate shares are roughly constant over time, this suggests that Ivy graduates held between 6 and 10 times as many executive positions as the average graduate in 2001, and between 8 and 12 times as many positions in 1980, depending on whether one uses the bachelor's or all-degree share. These figures aggregate across all majors and would likely rise if one focused on business-oriented fields.

${ }^{15}$ US statistics here and below calculated using Mobility Report Card data (Chetty et al. 2017).
} 
Within-program group differences in top attainment persist even after conditioning on observable pre-college ability. Panels E and F of Figure 1 show, respectively, average counts of leadership positions and the share of admitted students with top $0.1 \%$ incomes by position in the test score distribution for admitted students at elite programs. Conditional on program, cohort, and admissions score decile, male students from private high schools hold 2.6 (8.2) times as many leadership positions and are 3.4 (9.6) times as likely to have a top $0.1 \%$ income as male students not from private schools (female students). These findings motivate an analysis of heterogeneous effects by gender and high school type in the regression discontinuity setting.

The descriptive analysis thus far includes all applicant-year observations where the applicant is at least 12 years removed from college application, or approximately age 30. However, students generally do not reach top positions in the income distribution until mid-career. Figure 2 shows age profiles for log income and top $0.1 \%$ share by gender and high school type for students admitted to elite degree programs. Ages are calculated based on years since application. Gaps in log income between male private high school students and other groups rise over the career. Incomes in the top $0.1 \%$ are rare before applicants reach their late $30 \mathrm{~s}$. Top attainment then rises sharply for male private high school students, reaching $4.6 \%$ by age 50 . Increases are much smaller for the other two groups. With these findings in mind, the regression discontinuity analysis will focus on applicants at ages 40 and older, to allow time for applicants to advance their careers to the point where top outcomes are feasible.

\section{Regression discontinuity analysis}

\subsection{Estimation}

I use a regression discontinuity design generated by admissions cutoffs to provide evidence on the causal effects of access to elite business-focused programs. The goal of the discontinuity analysis is to understand how access to an elite program rather than a next-choice option helps students attain top positions. Effects of this type are of interest for applicants to elite programs waiting for admissions outcomes. Further, given observed substitution patterns (described in detail below), they reflect the effects of increases in selectivity within business-focused career paths. This is consistent with the broader goal of understanding the effects of elite access.

Several treatment concepts are potentially of interest here. These include the effect of admission to any of the business-focused programs at PUC and UC, the effect of admission to only the most selective program in each field, and the effect of marginal increases in selectivity at the top of the selectivity distribution. Patterns of substitution in the data allow me to construct estimates of 
each. Within each field, the PUC program is more selective than the UC program. Regression discontinuity estimates that compare students near the bottom of the published admissions lists to students near the top of the waitlists at UC programs therefore capture the 'any elite' treatment concept, while estimates using PUC applications capture the 'most selective' concept. I focus my analysis on the marginal increase in selectivity concept, which pools over UC and PUC applications, but also discuss UC- and PUC-specific effects.

I estimate two types of regression discontinuity specifications. I use the first type to study leadership outcomes. These specifications are of the form

$$
Y_{i p c}=f\left(d_{i p c}\right)+\Delta A_{i p c}+e_{i p c}
$$

where $Y_{i p c}$ is a leadership outcome for student $i$ applying to program $p$ in application cohort $c$. $d_{i p c}$ is $i$ 's score on application $p$ in cohort $c$ relative to the cutoff score, and $f()$ is some smooth function. $A_{i p c}=1\left[d_{i p c} \geq 0\right]$ is a dummy equal to one if $i$ is admitted to $p$ in cohort $c$. The primary outcome variable of interest is the count of C-suite and directorship positions that applicants hold. I also consider specifications where the dependent variable is a dummy for holding any such position, and specifications that separate by position type.

The second type of specification has the form

$$
Y_{i p c t}=f\left(d_{i p c}\right)+\Delta A_{i p c}+e_{i p c t}
$$

The second type is identical to the first except that the outcome variable has a panel component. I use specifications of this form to study outcomes observed in tax data, which vary across outcome years. The outcome I focus on is an indicator equal to one if an applicant has an income in the top $0.1 \%$ of the year-specific income distribution. I supplement this with indicators for surpassing other quantile thresholds and with log income.

The parameter of interest is $\Delta$, which captures the effect of admission to an elite program for marginal applicants relative to their next-choice option, averaged across degree programs and, in equation 2, outcome years (Cattaneo et al. 2016). I estimate these specifications using data on students near the admissions threshold. There is one cutoff for each program in each year. Following Pop-Eleches and Urquiola (2013), I summarize information from these cutoffs by 'stacking' data across all cutoffs. The use of stacked data means that some students may show up in the data more than once. For example, many students are rejected from degrees at PUC but admitted to programs in the same field at UC. To account for this in inference, standard errors 
are clustered at the student level throughout.

I focus on two versions of equations 1 and 2. The first version, which I refer to as the 'BW=10' specification, is a simple mean comparison of outcomes for students within a 10 point score window on either side of the admissions threshold. This specification does not include slope terms. The second version, which I refer to as the ' $B W=20$ ' specification, includes students within a 20 point window on either side of the admissions threshold. It allows for separate linear terms in scores above and below the cutoff. Point estimates for top outcomes are very similar across the two specifications. The BW=10 specification increases statistical power because of the restriction on slope terms. In the text, I refer to point estimates from this specification.

Online Appendix $\mathrm{C}$ discusses the selection of optimal bandwidths and polynomial degrees in more detail. Cross-validation procedures show that the polynomial degree that maximizes outof-sample fit is zero, even at relatively wide bandwidths (Tables C-1 and C-2). This is consistent with my focus on the BW=10 specification, and with the weak relationship between the running variable and top attainment away from the cutoff. Optimal bandwidth selection and standard error calculation procedures (Calonico et al. 2014, Calonico et al. 2016) do not materially affect inference. The inclusion of control variables and the use of Lee-Card (2010) standard errors also do not affect my findings (Table C-3).

\subsection{Regression discontinuity sample}

Table 2 shows mean values of student-specific covariates for a) the full applicant sample, b) the sample of marginal applicants within 20 points on either side of the admissions threshold, c) the sample of marginal male applicants, and d) the sample of marginal male applicants for whom data on high school type is available. The upper panel describes application-outcome year level data for applicants between 1980 and 1991, while the lower panel describes application-level data for students applying between 1974 and 1991. I use the former sample in my analysis of top incomes and the latter in my analysis of leadership positions. ${ }^{16}$

Applicants in the 1980-1991 sample have high scores on math and reading exams, with averages of 742 and 658 points, respectively, on tests that are normed to have a mean of 500 and a standard deviation of 100 in the population. I assign a high school type to $72 \%$ of records. Of this $72 \%, 48.2 \%$ attended private high schools. I observe $80.4 \%$ of applicants in the labor force sample, with an average earnings of $\$ 80,800$ per year. $1.8 \%$ of observations fall in the top $0.1 \%$

\footnotetext{
${ }^{16}$ Recall that tax data is available only for 1980 and later cohorts. Data on students' standardized math and reading scores are also available only for 1980 and later application years, although the composite indices used to determine admissions outcomes are available in all years.
} 
of the population income distribution. $76 \%$ of applicants are male. Male applicants have similar test score and high school backgrounds to the full sample, with higher rates of labor force participation, higher earnings, and a $25 \%$ higher probability of a top $0.1 \%$ income.

Applicants over the 1974-1991 period are similar to those in the 1980-1991 subsample in terms of gender and high school type. Rates of successful match to high school records are lower prior to $1980.2 .9 \%$ hold either a C-suite or directorship position. The average count of positions is 0.049 , or 4.9 per hundred students. $0.2 \%$ of applicants hold more than four such positions, with the maximum number of positions held being 16. These are applicants who hold seats on the boards of many companies. To limit the effects of outliers while still allowing for intensive margin effects, my discontinuity analysis topcodes the count of positions held at four. I report results using the raw leadership counts and an indicator for holding any leadership position in supplemental tables. Effect sizes and inference are not affected.

\subsection{Validating the discontinuity design}

Regression discontinuity estimates are unbiased only if determinants of leadership outcomes are balanced across the threshold. I consider two tests of cross-threshold balance. I first look for a discontinuity in the density of scores at the cutoff point (McCrary 2008). If more ambitious students are able to manipulate their test scores so as to fall just above the cutoff, one would expect a discontinuously higher density of scores at that point. Figure 3 shows a histogram of scores relative to admissions cutoff value. There is no evidence of clumping above the threshold. $31 \%$ of applications are within 10 points of the cutoff, $57 \%$ are within 20 points, and $84 \%$ are within 40 points. Figure A-1 shows separate density plots for students who attended private high schools and those who did not, as well for applicants to PUC and UC degree programs. Densities are smooth across the cutoff in each subsample.

I next check the balance of predetermined covariates across the threshold. Panels A through D of Figure 4 display binned means of indicator variables for gender, match to high school data, and private high school status conditional on match, as well as a linear, leadership-weighted index of application cohort and institution-major specific dummy variables. There is no evidence that these variables change discontinuously across the admissions threshold. I report balance regression results in Panel A of Table 3. 90\% confidence intervals include 0 for each of the 18 estimated coefficients. These include tests that subset on gender and high school type. Panel E of Figure 4 and the 'In LF sample' rows of Table 3 shows that elite admission does not affect labor

force participation rates. This reduces concerns about selective outmigration. Note that I use the full sample, including labor force non-participants, when estimating top income effects. 


\subsection{Changes in admissions outcomes across the threshold}

The interpretation of threshold-crossing estimates depends on the mix of degree programs to which students would otherwise be admitted. Figure 5 shows the effects of admission to an elite degree program on two measures of selectivity: peer mean math scores and the share of degree program peers from private high schools. The left, center, and right panels show results for the pooled applicant sample, applicants to UC programs, and applicants to PUC programs, respectively. ${ }^{17}$

In the pooled sample, admission to the target degree program is associated with a 9.1 percentage point increase in the share of peers from private high schools, and a 24.1 point gain in peer mean scores. Both peer scores and the fraction of peers from private high schools are lower for students admitted to the less-selective UC degrees than PUC degrees. Students admitted to the UC programs see the share of peers from private high schools rise by 5.3 percentage points from a base of $39 \%$, and average peer math scores rise by 24.8 points. Students admitted to the more selective PUC programs see the fraction of peers from private high schools rise by 18.4 percentage points from a baseline of $43 \%$ and peer math scores rise by 21.9 points.

The left two columns of Table 4 report these results (in the rows marked 'pooled', 'UC', and 'PUC') as well as results allowing heterogeneous threshold-crossing effects by gender and private high school background. Admission has similar effects on peer attributes across group. Male students experience somewhat larger gains in peer high school quality from admission, while students from private high schools experience smaller gains in peer high school composition and test scores.

The right three columns of Table 4 explore transitions across fields. Cells in these three columns display below-threshold mean values of dummy variables equal to one if a marginally rejected student is admitted to a degree program of the type listed in the column. These are the intercept terms in the regression discontinuity equation. Most rejected students are admitted to degree programs in the same or similar fields to the program they are targeting. In the pooled sample, $12.4 \%$ of marginally rejected students are admitted to the other elite degree program in the same field as their target, and $46.0 \%$ are admitted to a non-elite program in that field. Two thirds are admitted to a program in one of the three business-oriented fields.

Students rejected from the less selective UC programs almost always leave the elite set, while

\footnotetext{
${ }^{17}$ Below-threshold measures of peer characteristics are calculated using data for the $91 \%$ of marginally rejected students who are admitted to some degree program in the same year. Most remaining students are eventually admitted somewhere. Figure A-3 in the Online Appendix shows results where peer attributes are determined by the highestscoring (highest private school share) program to which a student is ever admitted. This data is available for $96.5 \%$ of marginal rejected students. Results are similar.
} 
students rejected from PUC programs typically end up at the UC program in the same field. $57.2 \%$ of students marginally rejected from UC degree programs are admitted to a non-elite program in the same broad field as their target program. $46.8 \%$ of marginal rejected students at PUC are admitted to the same program at UC while another $14.5 \%$ are admitted to a program in the same field at another institution. Students from private high schools are somewhat more likely to have another elite program as their next option, and male students are more likely than women to have another program in the same or similar fields. My main analysis focuses on specifications that pool across fields and across applications to PUC and UC, with supplemental discussion of UC- and PUC-specific findings.

Admissions effects matter insofar as they predict attendance. Data on matriculation are unavailable for cohorts used in the analysis of top outcomes, but they are available for more recent cohorts. I consider the matriculation effects of admission for these more recent students in Appendix Table A-2 and Figure A-2. Admission to an elite degree program raises the probability students matriculate at that program by more than 90 percentage points, with similar effects for men and women and for students from private and non-private high schools.

\subsection{Effect of elite admission on leadership and top income attainment}

Figure 6 shows how leadership and top income attainment change with elite admission. Within each panel, the left graph shows results for the pooled sample and split by gender while the right panel splits male students by high school type. Discontinuities are easily observable in the pooled sample for each outcome. Elite admission raises the rate at which students obtain incomes in the top $0.1 \%$ of the distribution by $50 \%$ ( 0.007 from a below-cutoff base of 0.014$)$, and the count of leadership positions students hold by $44 \%$ ( 0.013 from a base of 0.030$)$. In both cases, zero effects lie outside of a $99 \%$ confidence interval.

The effects we observe in the pooled sample are driven by male students from private high school backgrounds. As shown in the left graph in each panel, admission raises male students' chances of attaining a top $0.1 \%$ income by $50 \%$ ( 0.009 from a base of 0.018$)$, and the number of leadership positions they hold by $54 \%$ (0.019 from a base of 0.036$)$. Effects for women are close to zero when the outcome is top income, and slightly negative for the leadership outcome. As shown in the right graph, within male students, gains accrue only to students from private high school backgrounds. For male students from private high schools admission to an elite degree raises the chances chances of attaining a top $0.1 \%$ income by $69 \%$ ( 0.022 from a base of 0.032$)$, and the count of leadership positions by 54\% (0.032 from a base of 0.059 ). Admissions effects for 
male students not from private high schools are close to zero. ${ }^{18}$

The left two columns of Table 5 display regression estimates of threshold crossing effects on top $0.1 \%$ income and leadership outcomes in the $\mathrm{BW}=10$ and $\mathrm{BW}=20$ specifications. Within each subsample, estimates are nearly identical across specifications. This is because the relationship between the running variable and top-end labor market outcomes is weak in the neighborhood of the cutoff. ${ }^{19}$ In the BW=10 specification, 99\% confidence bands for estimated effects generally exclude zero in the samples of all students, male students, and male private high school students. Tthe one exception is the leadership effect for private high school students, for which the p-value from a two-sided test of a null of zero is 0.018. I can reject equality of effects by gender and high school type at the $\mathrm{p}=0.05$ level for both outcomes. Additional slope terms in the $\mathrm{BW}=20$ specification reduce precision. However, p-values from tests of main effects and cross-group differences against a zero null remain in the 0.01 to 0.10 range.

\subsection{Effects of admission on other income measures}

Figure 7 and the right three columns of Table 5 show how admission changes the probability that students reach the top $1 \%$ and top $10 \%$ of the income distribution, and how admission affects log income. Cross-threshold changes in these outcomes follow similar patterns to those observed for top $0.1 \%$ income and leadership outcomes. In each case, elite admission raises income for male students from private high schools. Elite admission raises the chances a male private high school student has an income in the top $1 \%$ by $33 \%$ ( 0.054 on a base of 0.163 ) and in the top $10 \%$ by $13 \%$ ( 0.065 on a base of 0.52$)$. Income for this group rises by about $20 \%$. For female students and for male students not from private high schools effects are close to zero. Findings for these outcomes rule out the hypothesis that top-end gains are small for female and non-private school students because their incomes are too low for top outcomes to be feasible even with large overall gains. To complete the picture of how admission to elite degree programs affect the earnings distribution, Figure A-4 presents admissions effects on the probabilities students reach a set of quantiles ranging from the top $0.1 \%$ to the top $25 \%$, with results paralleling those presented in

\footnotetext{
18 There is some visual evidence of a downward slope in leadership outcomes for private high school students below the admissions threshold (right panel of Figure 6.B). This slope is not statistically significant $(p=0.49)$, and results from changes in the distribution of application cohorts and target degree programs as distance from the cutoff grows. Within applicants applying to a given program in a given year, there is no evidence of a negative belowthreshold slope. Online Appendix Figure A-5 presents an alternate version of the graph that residualizes outcomes on target-program by application cohort dummies before plotting. This eliminates the slope but does not affect the discontinuity. The slight negative slope in top incomes for admitted private high school students (bottom right panel) is also statistically insignificant $(\mathrm{p}=0.34)$. It does not appear in other top income measures (see Figures 7 and A-4).

${ }^{19}$ I cannot reject the hypotheses that slope terms are equal to zero in the BW=20 specifications at conventional levels. As shown in Online Appendix tables C-1 and C-2, the inclusion of slope terms leads to worse out of sample prediction even at wide bandwidths
} 
the main text.

\subsection{Interpreting effect sizes}

The economic magnitudes of the discontinuity estimates are large. One way to quantify them is as fractions of achievement gaps by gender and high school background. Male students admitted to elite degree programs during the regression discontinuity sample period reach the top $0.1 \%$ of the income distribution in $2.9 \%$ of earnings years, compared to $0.3 \%$ for women. The difference between admissions effects for men and women is 0.9 percentage points, equal to $36 \%$ of the gender gap. Male private high school students admitted to elite programs in the sample period are 3.9 percentage points more likely to have top $0.1 \%$ incomes than male students from non-private school backgrounds. The difference in admissions effects between these two groups is 2.1 percentage points, or $54 \%$ of the difference in means. For the leadership positions, the admissions effect for men relative to women (private school vs. non-private school men) is equal to $35 \%(31 \%)$ of the cross-group difference in mean outcomes for admitted students.

A second approach is to consider how causal effects scale relative to the population of corporate leaders and top incomes. A back-of-the-envelope calculation is helpful here. Say that all students admitted to an elite program were instead sent to their next best option (i.e., the program they would attend if rejected from a target elite program), and assume that the percentage effects of admission observed at the margin extend to all admitted students. The effect of admission to a preferred elite degree program in the pooled sample is to raise the rate at which students attain top $0.1 \%$ incomes (leadership positions) by $51 \%$ (44\%), so below-threshold mean values are equal to $66 \%(69 \%)$ of values for admitted students. Further, as discussed above, students at elite programs hold 39\% (41\%) of all top incomes (positions). The proposed change in admissions outcomes would therefore reduce the total count of income-years above the $0.1 \%$ threshold in the population by $13 \%(=(1-0.66) \times 0.39))$ and the count of leadership positions by $13 \%=$ $(1-0.69) \times 0.41))$ as well. Though this counterfactual is unrealistic for a number of reasons, it illustrates that the causal effects of elite business education may have first-order impacts on the composition of top incomes and corporate leadership as a whole.

\subsection{Heterogeneous effects and alternate outcome measures}

Online Appendix D considers how effects vary by institution, major, disaggregated student background, and alternate measures of top outcomes. Key points are as follows. First, patterns of leadership and log income effects are similar for the PUC and UC programs, while top income 
effects accrue predominantly to PUC admits (Table D-1). The finding that top income effects accrue mostly to PUC admissions suggest that the premium from attending the most selective program may be particularly large. However, I cannot in general reject equality of institutionspecific estimates.

Second, top income and leadership effects are larger for law and business degrees than for engineering degrees, with similar log income effects across the three fields (Table D-1). Third, admission increases the rates at which students attain both C-suite and directorship positions, as well as their chances of holding any leadership position (Table D-3). Effects estimated using non-topcoded counts of leadership positions are nearly identical to those reported above, and $\log$ income specifications that winsorize low income values produce similar findings to those reported in Table 5. Fourth, I consider the possibility that admission to elite degree programs leads to top career attainment in less remunerative sectors, such as government or education. I find no evidence of such effects (Table D-5).

Fifth, top income, leadership, and log income effects are larger for students from seven elite private high schools (distinguished by high prices, high test scores, and selective admissions) than from other private high schools, while effects for students from the most selective public exam high school in Chile are zero (Table D-2). The selective public school has similar test scores to the elite private high schools, but is free to attend. These findings suggest that differences in academic rigor at the high school level do not drive differential returns.

\section{Interpreting the effects of elite admission}

\subsection{Why are gains for male private high school students so large?}

The rest of the paper asks why elite business degree programs yield increases in top attainment only for male students from wealthy backgrounds. A number of explanations are possible, including differences in a) academic preparation, b) geographic preferences and constraints, c) interest in business careers, d) academic success in college, and e) success in forming valuable peer relationships in college. Which of these channels matter has implications for the efficacy of policies aimed at raising returns for other groups. This section shows that it is hard to explain the large gains for private high school men using mechanisms a) through d). It also shows that findings of differentially high returns for high-SES male stuents are specific to business fields and not a general feature of the high-skilled labor market in Chile. For concision I focus mainly on comparisons between male students from private- and non-private school backgrounds. 


\subsection{Effects by correlates of high school background}

Private high school status may be correlated with other student attributes besides SES that drive differential returns to admission. Though the presence of such correlates would not affect the central finding that admission to top business programs raises rates of top attainment only for students from high-SES backgrounds, it might affect the interpretation of this finding. For example, if marginal private high school students had higher math subject scores than marginal students from other backgrounds, and admissions effects conditional on math scores were equal across high school type, this would suggest that improving math instruction in public schools might help equalize the returns to elite business admission.

Table 6 explores this possibility. Panel A describes how observable characteristics differ by high school type in the sample of marginal male applicants. For each high school type, it presents means of math test scores, reading test scores, and an indicator variable equal to one if a student's high school is located in Santiago. I choose these covariates because they are available in a consistent form in each application cohort beginning in 1980 or earlier. The test score variables capture multiple dimensions of student ability that may differ by high school type. The geographic indicator is informative because it may capture, e.g., preferences over region that affect earnings outcomes through geographic variation in price levels.

Differences by high school type are small. Students from private high schools have math and verbal test scores that are 7.8 and 4.8 points higher than students from non-private high schools, respectively. These gaps fall to 4.5 and 3.7 points after conditioning on target program. Recall that each test section has a standard deviation of 100. The small size of these gaps indicates that marginal students from different backgrounds have similar levels of academic preparation. Private high school students are 12 percentage points more likely to come from Santiago, on a base of $70 \%$.

Panel B directly tests the effects of allowing heterogeneity on these dimensions on estimated effects by high school background. I estimate regression discontinuity specifications that allow for a main admissions effect and an interaction between admission and each variable listed in the columns. The specification also includes a constant term, an admissions main effect, and controls for main effects of each column variable. I find no evidence of effect heterogeneity on dimensions besides high school type. Further, allowing for additional heterogeneity does not affect estimates by high school type. This holds for each outcome: leadership, top $0.1 \%$ incomes, and log income. These findings are consistent with the hypothesis that SES drives effect heterogeneity by high school type. Panel C extends the analysis from Panel B by estimating heterogeneous admissions effects for private high school students within the sample of students from Santiago high schools 
only. Estimates of the gap between effects for private and non-private high school students are unchanged. Differential rates of inmigration to Santiago for students from private and nonprivate high schools do not drive differential effects by school type.

\subsection{Admissions effects on career paths}

\subsubsection{Changes in sector of employment}

As reported in Table 4, admission to elite degree programs is associated with increasing selectivity, as measured by peer scores or high school backgrounds. For a minority of students it is also associated with a change in field of study. Changes in rates of top outcome attainment may stem from either or both of these transitions. To the extent that there are differential changes in career path for male private school students, this could help explain why gains for this group are larger. I explore this issue first by considering the effects of elite admission on students' career paths using data on the broad sector of the firms where students work. If changes in top attainment are driven by students switching from, say, careers in journalism to careers in finance, we would expect to observe changes in the allocation of students to sectors across the admissions threshold. Data on sector of employment are available for just over $70 \%$ of application-outcome year observations. ${ }^{20}$ I create dummy variables corresponding to employment in different sectors and use them as dependent variables in Equation 2.

Table 7 presents estimates of threshold-crossing effects as well as below-threshold means (i.e., intercept terms) for selected sectors in the sample of male students. Marginal rejected students are most likely to work in business-oriented sectors. Three sectors (the real estate, rental, or business activities sector, the wholesale and retail trade sector, and the finance sector) account for $45 \%$ of observations. These three sectors make up large shares of employment for both students from private high school backgrounds (47\%) and non-private backgrounds (41\%). Students from non-private high schools are more likely to work in education or public administration (22\% of observations vs. $14 \%$ for students from private schools). Threshold-crossing has limited effects on sector mix. The largest effect is to reduce the fraction of students going into public administration by 2.9 percentage points. This effect is similar for students from private and non-private high school backgrounds.

I summarize the effects of sector switching using a linear index that regresses top $0.1 \%$ attainment on sector dummies (including a dummy for missing sector information). The income-weighted sector index rises slightly across the threshold in the pooled sample and for both high school

\footnotetext{
${ }^{20}$ These are students who have labor income from long-term contracts.
} 
types. Results are reported in the row labeled 'index.' Effects are positive in the pooled sample and for each high school type, but small in magnitude. For example, for private high school students the change in sector index is equal to $10 \%$ of the overall effect on top income attainment. Findings here suggest that students applying to business-focused programs from both privateand non-private high school backgrounds tend to pursue business-oriented careers, but that students from private high schools do so more successfully. Changes in sector of employment do not explain differential gains for private school students.

\subsubsection{Earnings outcomes by below-threshold admission outcome}

I next investigate the relative importance of changes in selectivity and changes in major using data on student choice lists. Beginning in 2000, application records include full student choice lists in addition to data on realized admissions and waitlist outcomes. The choice lists allow me to compare outcomes for students based on differences between their target program and their next option. For example, I can look at the effects of admission to elite degree programs only for students who would be admitted to a non-elite degree program in the same field if rejected from the target. The downside of these data is that students applying to college in 2000 or later have not yet reached their peak labor market years, so I cannot look directly at leadership or top incomes. Nevertheless, the exercise provides a useful complement to the finding that elite admission results in limited changes in sector of work over the long run. The approach resembles Kirkeboen et al. (2016), but with an emphasis on selectivity as opposed to field of study.

My analysis focuses on students applying to college in between 2000 and 2003. I consider only student-year observations where students are at least 10 years removed from the year of application, or age 28. The data cover applicants to the six elite, business focused degree programs. Based on student choice lists and test scores, I simulate counterfactual admissions outcome that would occur for each student if he were rejected from his targeted degree program. I label this program the next option. Appendix E discusses these data in more detail.

I estimate specifications of the form

$$
y_{i p c t}=\Delta^{0} A_{i p c}+f^{0}\left(d_{i p c}\right)+\sum_{n} X_{i p c}^{n} A_{i p c} \Delta^{n}+\sum_{n} X_{i p c}^{n} f^{n}\left(d_{i p c}\right)+e_{i p c t}
$$

As in Equation 2, $y_{i p c t}$ is a labor market outcome for individual $i$ applying to program-cohort pair $p c$ in outcome year $t . d_{i p c}$ is an individual's score relative to the cutoff and $A_{i p c}$ is an admissions dummy. Equation 3 differs from Equation 2 in that in addition to the main effect of admission $\Delta^{0}$ and smooth function $f^{0}\left(d_{i p c}\right)$, both admissions effects and smooth functions are allowed to vary 
with covariates $X_{i p c}^{n}$. The $X_{i p c}^{n}$ capture differences between attributes of the target degree and the next option degree for each student. To understand these specifications, it is helpful to consider a simple case in which there is only one binary $X_{i p c}^{n}$-say, an indicator equal to one if the alternative degree is in a business-focused field. In this case estimating Equation 3 is numerically equivalent to estimating separate RD specifications in the two groups defined by the binary dummy. $\Delta^{n}$ is equal to the difference between effect estimates between the two groups.

In practice, I estimate specifications that include multiple $X_{i p c}^{n}$, as well as non-binary $X_{i p c}^{n}$ such as the difference in peer scores and peer private high school share between the target and next option degree. Relative to standard RD estimation, these specifications impose the restrictions that a) the $X_{i p c}^{n}$ interact with $A_{i p c}$ and $f^{n}$ in an additively separable way, and b) that continuous variables interact linearly with the $A_{i p c}$ and $f^{n}$. These restrictions allow for tractable estimation of heterogeneity along several characteristics simultaneously. The separability restriction is similar to Kirkeboen et al. (2016). I take log income as the outcome of interest, and focus on the BW=20 specification because, as discussed above, the running variable is predictive of log income. See Online Appendix E for results from the BW=10 specification (Table E-3), as well as balance tests (Table E-2), discontinuity graphs (Table E-2), and sample descriptions (Table E-1).

Table 8 presents results. Panel A presents estimates that include a main effect term as well as interactions between admission and a) the gap in peer mean math scores at the target versus the next option field, b) the gap between share of private high school students at the target versus next option program, c) an indicator equal to one if the next degree program is not in the business, engineering, or law fields and d) a dummy variable equal to one if the next option is also an elite program. Peer score gaps and high school share gaps are demeaned, so that the main effect captures the effect of admission to an elite program for a student whose next option is a non-elite program in a business area with mean test scores 25 points below the target degree and peer private high school share 13 percentage points below the share at the target program.

Key findings are as follows. First, increases in the fraction of students from private high schools are strongly associated with earnings gains, holding other factors constant. The earnings gains associated with increases in peer private high school share are larger for students from private high school backgrounds and close to zero for students not from private high school backgrounds. In contrast, there is little evidence that students who move to degree programs with higher peer scores experience earnings gains. Second, students who would otherwise be admitted to degrees in non-business areas may realize larger gains than those coming from business areas, but this difference is noisily estimated. At minimum, gains are not limited to students transitioning from business to non-business fields. Finally, having another elite institution as your 
fallback option reduces the earnings gains from admission to your target elite program. ${ }^{21}$

Panel B of Table 8 displays earnings effects by terciles of the cross-threshold change in peer private high school share for private high school students. This confirms that in the pooled sample and for private school students earnings effects are largest for students with biggest gains in peer private high school share in an RD setting that does not impose the separability or linearity assumptions in Equation 3. In contrast, the relationship between earnings effects and changes in peer high private high school share are less clear for students not from private high schools. For this group I cannot reject a null hypothesis of zero effect in any tercile and the largest positive effect is in the second tercile. The takeaway from this analysis is that increased degree program selectivity within business-focused fields is a key driver of the observed labor market effects for private high school students, with peer SES background a much stronger correlate of earnings gains than peer scores.

\subsection{Contrast with elite programs in other fields}

I next consider whether differential returns to elite education are a general feature of the Chilean labor market or are specific to business degrees. The former story would contrast with evidence from the US that returns to selective education are larger on average for lower-SES individuals (Zimmerman 2014; Dale and Krueger 2011). The latter story suggests a focus on mechanisms that can differentiate the determinants of returns to business careers from those in other disciplines.

Prior research on major-specific earnings returns in Chile suggests that elevated returns for highSES students are specific to business programs. In analysis of earnings returns across the distribution of degree programs, HNZ show that business is the only broad field of study that offers high average returns to high-SES students but small or zero returns to students from other backgrounds. Here, I use a comparison between elite business programs and elite medical programs to show that high returns are available to non-private school students and women at the top of the selectivity distribution, just not in business fields. As shown in section 3, the top medical degree programs are the only program type where selectivity and average earnings are similar to what is observed at the top business programs. To compare the the effects of admission to elite business degree programs to medical admission, I repeat the regression discontinuity analysis using data on applicants to the medical programs at PUC and UC. ${ }^{22}$ Figure 8 summarizes key findings, with more details in Appendix F.

\footnotetext{
${ }^{21}$ As per Table 4 , students with elite next options are typically students on the margin of admission to PUC who attend UC if rejected.

${ }^{22}$ As with business fields, medical programs at these two institutions are the most selective in Chile.
} 
Panel A of Figure 8 shows that, in contrast to elite business degrees, admission to elite medical degrees raises the rate at which both men and women (left panel) and men from private and nonprivate school backgrounds (right graph) reach the top $10 \%$ of the income distribution. Gains are larger for women than for men, and for non-private school men than for other men, so that gaps in rates of attaining a top $10 \%$ income by gender and high school type fall sharply across the threshold. As reported in Table F-2, similar findings hold up for entry into the top 5\% of the distribution and for log income.

Though admission to elite medical programs closes gender and income gaps in rates of attainment of incomes near the top, it has almost zero effect the rate at which students reach the top $0.1 \%$. Panel B of Figure 8 reproduces the $0.1 \%$ attainment graph for business applicants by high school type (left graph) and compares it to the equivalent graph for medical applicants (right graph). The rates at which medical applicants attain incomes within the top $0.1 \%$ is near zero, regardless of admissions status. The leveling effects observed at lower quantiles are not present here. As reported in Table F-2, results for reaching incomes in the top 1\% are similar. The takeaway point is that although elite degrees in non-business fields reduce income gaps by gender and baseline wealth and can yield high incomes on average, they do not provide a path to the top of the income distribution.

\subsection{Differential educational attainment}

The comparison between elite business and medical programs also provides suggestive evidence on the importance of differential academic achievement as a driver of heterogeneous returns. The approach here is to compare cross-group differences in college completion rates to crossgroup differences in labor market outcomes. ${ }^{23}$ Because graduation data is not systematically available prior to 2000 or after 2015, I study graduation outcomes using data from the 2000 through 2005 entering cohorts. Table 9 presents 10-year graduation rates for students admitted to elite business and medical programs from any higher education degree program (the 'any' column) and from the university to which they were admitted (the 'target' column). The table splits by gender and high school type.

Differences in graduation rates by demographic groups bear a weak relationship to differences in labor market outcomes. Graduation rates are high overall. 80\% (95\%) of admitted business students (medical students) graduate from some degree program, and 70\% (91\%) graduate from the degree to which they are admitted. In both fields, graduation rates are higher for women than

\footnotetext{
${ }^{23}$ I take college completion as a measure of student performance. This is common in the returns to college literature. See e.g. Zimmerman 2014, Goodman et al. 2015. More direct measures of learning such as grades of performance on post-college standardized test (Riehl et al. 2017) are not available here.
} 
for men, and higher for male private school students than male students not from private high schools. Women admitted to an elite business program are 5.3 percentage points more likely to obtain a higher education degree than men admitted to the same program. The gap for medical admits is 3.4 percentage points. Male private school students are 11.0 percentage points more likely to complete than non-private high school students admitted to the same program, with a gap for medical admits of 6.7 percentage points. ${ }^{24}$

That women admitted to business programs are more likely to graduate than men suggests school performance cannot explain differences in the return to admission by gender, and in particular cannot explain zero return to admission for women. Similarly, the fact the gaps in graduation by high school type show up in both medical and business fields- where the relative effects of admission on labor market outcomes by high school type have opposite signs- suggest that differences in academic performance by high school type are not the key driver of crossgroup differences in labor market effects. These results are consistent with a broader literature arguing that elite education at the high school level (Dobbie and Fryer 2014, Abdulkadiroğlu et al. 2014, Angrist and Rokkanen 2015) has little effect on learning outcomes. If elite admission does not affect learning, then differential learning does not drive differential labor market outcomes. They are also consistent with findings at the college level. Riehl et al. (2017) use data on pre- and post-college testing to show that a) top private institutions and b) business, law, and engineering majors overperform on measures of earnings value-added relative to how much students learn.

\section{Peer ties as a mechanism}

The final causal channel I consider as driver for high returns among male private high school students is peer ties. Previous studies suggest that ties between former classmates may be particularly important in high-status corporate settings (Kantor 2013; Shue 2013; Fracassi and Tate 2012). Peer ties may benefit students in several ways. Students at elite universities may have ties to businesses through which they can refer college peers. Alternatively, school peers may be more productive if they work together, and working with peers may incentivize good performance at work. Students from private high school backgrounds could benefit disproportionately if they are better able to form valuable ties with their college peers.

An empirical challenge for the study of peer ties is separating the effects of peer relationships

\footnotetext{
${ }^{24}$ Figure A-6 shows standard RD plots for the two graduation measures, splitting by gender and high school type respectively. As expected, admission sharply raises the rate at which students graduate from their target institution. Admission has small or zero effects on whether students graduate from any institution.
} 
from other common inputs available at top schools. The approach here is to look at co-leadership rates, which I define as the probability that both members of a pair of students have leadership roles at the same firm. Focusing on male students, I compare co-leadership rates for students who were college peers (i.e., who attended the same degree program at the same time) to coleadership rates for pairs who attended the same degree program at different times, or who attended a different degree program at the same time. The intuition is that within a degree program, same-cohort pairs are similar to pairs of students a few years apart in terms of precollege backgrounds and institutional inputs, but that students in same-cohort pairs are more likely to know each other and to have mutual contacts. If students obtain jobs through contacts, or if peers are more productive when working together, college peers may be more likely to serve on leadership teams at the same firms than other pairs of similar students. If management hiring depends only on non-peer institutional inputs, there would be little reason to expect such a result. The the pairs-based empirical strategy is most closely related to Bayer, Ross, and Topa (2008), who explore how the probability two individuals work at the same address depends on how close together they live.

Panel A of Figure 9 presents co-leadership rates by cohort distance for male students in the same degree program and students in the other elite degree program in the same field. The sample includes only pairs of students where both members of the pair are from private high schools (though not necessarily the same private high school). I present separate figures for all private high school students (left graph) and for the subset of private school students from elite private schools (right panel). Recall from Section 4.8 that leadership gains across the admissions threshold were largest for students from elite private high schools. Co-leadership rates are expressed on a per-100,000 pairs basis. One way to think about the group means is as the number of coleaders who would emerge from a group of about $317(\approx \sqrt{100000})$ students. This is roughly the size of the admitted cohort in the engineering program at PUC during the period studied here. In both panels, co-leadership rates for students in the same degree program are relatively flat by cohort distance for students one or more year apart, but much higher for students who are peers in the same program in the same cohort. In contrast, there is no obvious pattern in co-leadership rates by cohort distance for students in different programs in the same field. This indicates that the elevated rates for peers are not driven by a propensity for non-peer students in the same cohort and same field to lead the same firms over the long run.

Panel B of Figure 9 displays co-leadership rates for pairs of students from private high schools by the position of the applicant relative to the admissions cutoff. I focus on the way admission changes applicants' co-leadership outcomes with three types of students: admitted students at the target degree program (e.g., the law program at PUC) in the same application cohort (i.e., students who will be applicants' college peers), admitted students at the target degree program 
separated by at least one year, and students from different degree programs in same field and same admission cohort. In contrast to the regression discontinuity graphs presented above, Panel B of Figure 9 displays binned means within a 40 point window on each side of the admissions threshold, and uses a wider bin width. Rates of co-leadership are relatively low compared to overall leadership rates, ${ }^{25}$ reducing statistical power. I therefore focus this discussion on a) broad comparisons of means above and below the threshold, and b) global polynomial specifications that allow for separate slopes above and below the threshold rather than a local regression discontinuity analysis.

Students who are not admitted to their target program are similarly likely to co-lead firms with students accepted to the same cohort in their target program, with students accepted to other cohorts in that program, and with students from nearby cohorts in other same-field degree programs. Students admitted to their target program become roughly three times as likely to co-lead firms with their college peers, but are no more likely to co-lead firms with other types of admitted students. For example, a student admitted to PUC Law class of 1983 is much more likely than a student rejected from that degree program to serve on the same corporate board as another PUC Law student from the class of 1983. However, he is no more likely than the rejected student to serve on the same corporate board as a student from the PUC Law class of 1980, or from the UC Law class of 1983. Statistical tests reported in Table A-3 reject the hypothesis that the observed gain in co-leadership for same degree, same cohort pairs is equal to zero, but fail to reject the hypothesis that co-leadership gains for other pair types are zero.

These results are consistent with a story in which ties between peers from private high schools play an important role in driving the increase in leadership hiring associated with admission to an elite degree program. It is natural to ask whether students from non-private high schools also benefit from peer ties at elite degree programs. The finding of no causal effect of admission in the regression discontinuity analysis suggests they may not. To explore this question I estimate single-difference specifications of the form

$$
Y_{i j}=\alpha+\sum_{g} C_{g}\left(t_{i}, t_{j}\right) \pi_{g}+e_{i j}
$$

within the sample of applicant pairs admitted to the same degree program, and difference-indifferences specifications of the form

\footnotetext{
${ }^{25} 428$ male students from private high schools admitted to elite degree programs between 1974 and 1991 held at least one leadership position. Of these, $258(60 \%)$ held a positition at the same firm as another private school student from the same field, and $195(46 \%)$ with a private school student from the same program, and $78(18 \%)$ with a private school student from the same program and at most one cohort apart.
} 


$$
Y_{i j}=\alpha+\beta S\left(p_{i}, p_{j}\right)+\sum_{g} C_{g}\left(t_{i}, t_{j}\right) \gamma_{g}+\sum_{g} S\left(p_{i}, p_{j}\right) C_{g}\left(t_{i}, t_{j}\right) \pi_{g}+e_{i j}
$$

in the sample of applicant pairs admitted to same-field elite degree programs. $Y_{i j}$ is a dummy equal to one if $i$ and $j$ hold leadership positions in the same firm. Denoting the application year for applicant $i$ as $t_{i}$ and the program where $i$ is admitted as $p_{i}, C_{g}\left(t_{i}, t_{j}\right)$ is an indicator function equal to one if $\left|t_{i}-t_{j}\right|=g$, while $S\left(p_{i}, p_{j}\right)$ is an indicator equal to one if $p_{i}=p_{j}$. The coefficients of interest in both equations are the $\pi_{g}$. High values of $\pi_{0}$ relative to estimates for larger $g$ indicate higher rates of co-leadership for college peers relative to non-peers. Equation 4 compares co-leadership rates for college peers relative to non-peers admitted to the same program, while equation 5 uses both same program and same field, different program students as controls. In both specifications, $g$ takes values between zero and three, with values of $g$ greater than or equal to four pooled into a single omitted category. For students from private high schools, estimates of Equation 4 are equivalent to comparing the same-program co-leadership rates in Panel A of Figure 9 to the value for $g=4$, while estimates of Equation 5 can be obtained by differencing out the other-program effects and then making the same comparison.

As is standard in difference-in-difference analyses, the key assumption underlying the interpretation of $\pi_{0}$ as a causal effect of peer status on co-leadership outcomes is that firm-program effects and firm-cohort effects are additively separable; i.e., that there are not differential changes in the skill match between degree programs and firms over time. In practice, it is difficult to conclusively rule out violations of separability. That co-leadership rates are elevated only for students exposed to each other in the classroom helps alleviate this concern, as does the finding of a discontinuous break in co-leadership rates for admitted students.

Table 10 presents results. Panel A presents estimates of the $\pi_{g}$ from Equation 4 and Panel B from Equation 5. The first two columns present estimates for pairs of students in which, respectively, both members of a pair are from private schools, and both members of a pair are from elite private schools. Effects are expressed relative to the omitted category of a four or more year cohort gap. As expected we see elevated rates of co-leadership only for students who are peers in the same cohort. Zero effects fall outside of a $90 \%$ confidence interval in each specification. The single-difference specification indicates that students who are peers in the same cohort in the same program are $126 \%$ more likely to lead the same firm than students separated by four or more cohorts. For students from elite private high schools only, the effect estimate in percentage terms is $137 \%$. Difference-in-difference estimates are slightly larger than single-difference estimates.

The third column in Table 10 shows effects for pairs of elite admits where one member is from 
a private high school and another member is not. Overall rates of co-leadership are lower for such pairs, and estimated peer effects are small. The fourth column of Table 10 shows estimates for pairs of students where neither member has a private high school background. Estimated peer effects are small here as well. The estimated effect at $g=0$ in the difference-in-differences specification is significant at the 10 percent level. I interpret this effect cautiously because it is not replicated in the single difference specification. As shown in Figure G-1, there is no visual evidence of a spike in co-leadership rates for peers in either the mixed-school type or non-private school samples.

The analysis of co-leadership rates shows that a) students from private high school backgrounds who are admitted to elite degree programs become more likely to lead firms with their samebackground college peers, but not with same-background non-peers, and b) that students not from private high schools are no more likely to lead the same firms as their peers regardless of background. These findings are consistent with the idea that ties to college peers play an important role in determining top outcomes. In particular, the finding that admission to an elite university does not increase in rates of co-leadership with non-peers is hard to reconcile with stories where elite programs raise leadership through non-peer channels.

Online Appendix G formalizes this intuition using a simple model of leadership hiring in which hiring depends on student skills and referrals from school peers. The model maps gains in coleadership rates with non-peers to skill effects, and differentially large gains in co-leadership rates with peers to peer effects. It provides the basis for a decomposition of the total effect of admission into a 'skill' component and a 'peers' component using the co-leadership estimates presented here. Intuitively, defining a simple hiring process allows me to scale differential rates of co-leadership for peers and non-peers to overall leadership rates by comparing the relative frequency of leadership and co-leadership. Results from this exercise suggest that peer ties can account for essentially all of the observed effect. The caveat is that the decomposition relies on a restrictive model of the hiring process. More detailed explorations of how peer ties affect leadership hiring is a subject for future research. ${ }^{26}$

\section{Discussion}

This paper asks whether elite colleges provide a pathway for talented students to positions at the top of the income distribution and leadership roles at major firms. I combine novel data on ap-

\footnotetext{
26 Online G also presents additional results showing that inference is robust to alternate methods of calculating standard errors (Table G-1), that peer effects in college accrue to private high school students whether or not they attended the same private high school (Table G-2), and that increases in rates of co-leadership are driven by pairs that include at least one directorship position (Table G-2).
} 
plicants to elite business, law, and engineering programs in Chile with a regression discontinuity design that exploits score-based admissions cutoffs. I link these records to data on top managers and directors at all publicly traded firms in Chile and to administrative tax records. Descriptive results show that students admitted to elite degree programs account for $41 \%$ of leadership positions and $39 \%$ of the top $0.1 \%$ of the income distribution for college admissions test takers aged 30 and over, despite making up just $1.8 \%$ of this population. Admission to an elite degree program raises the number of leadership positions students hold by $44 \%$, and their probability of attaining income in the top $0.1 \%$ of the distribution by $51 \%$. However, the gains accrue only to male students who attended expensive private high schools. Female students and male students who attend other types of high schools, including elite public schools, do not realize any gains from elite college admission.

The effects I observe are the result of increased success in business-focused careers, not shifts to business from other sectors. Differences in returns by SES and gender cannot easily be attributed to differences in academic achievement or features of the Chilean labor market that reduce earnings for disadvantaged groups across all career paths. This suggests that features of the labor market specific to business careers drive cross-group differences in admissions effects. The composition of leadership teams at particular firms suggests that ties formed between college peers from private high schools are one important mechanism. Difference-in-difference estimates show that private high school students who are peers in the same degree program are $126 \%$ more likely to lead the same firms than are non-peers, but that students who are not from private high schools are no more likely to lead firms with peers than with non-peers. These findings are hard to reconcile with mechanisms based on general or firm-specific human capital accumulation.

As in the US, elite colleges in Chile view identifying and developing talented students from nonelite backgrounds as an important part of their mission (Agosin 2012; Lewis 1997). My findings suggest that access to elite education can help students reach income levels near the top of the distribution, but not at the top. They indicate several avenues for future research. The first is whether efforts to increase social integration at the secondary or postsecondary level- such as roommate or study group randomization (Sacerdote 2001, Shue 2013) - can raise top attainment for lower-income students at elite degree programs. The second is whether the importance of peer ties as a determinant of managerial attainment has implications for the efficiency of corporate management. Though peer ties may reduce efficiency by encouraging lax oversight (Fracassi and Tate 2012; Shue 2013), it is possible that signals conveyed through peer ties facilitate information flows (Cohen et al. 2008), lead to peer complementarities in production (Oyer and Schaefer 2012), or mitigate agency problems (Caselli and Gennaioli 2005, 2013). The third involves the relationship between the determinants of mobility and economic growth. Competition amongst 
elites is a key driver of economic growth over the long run (see e.g. Acemoglu and Robinson $2000,2006,2008,2012$ ). The failure of elite universities to facilitate upward mobility to top positions may be a cause or a consequence of elite entrenchment.

\section{References}

Abdulkadiroğlu, Atila, Joshua Angrist, and Parag Pathak, "The elite illusion: Achievement effects at Boston and New York exam schools," Econometrica, 2014, 82 (1), 137-196.

Abdulkadiroglu, Atila, Joshua D Angrist, Yusuke Narita, Parag A Pathak, and Roman A Zarate, "Regression Discontinuity in Serial Dictatorship: Achievement Effects at Chicagos Exam Schools," American Economic Review, 2017, 107 (5), 240-245.

Acemoglu, Daron and James A. Robinson, "Political losers as a barrier to economic development," The American Economic Review, 2000, 90 (2), 126-130.

and __ , Economic backwardness in political perspective," American Political Science Review, 2006, 100 (1), 115-131.

and _ "Persistence of Power, Elites, and Institutions," The American Economic Review, 2008, 98 (1), 267-93.

and _ Why Nations Fail: The Origins of Power, Prosperity, and Poverty, Crown Business, 2012.

Agosin, Manuel, “Standard Alignment Plan FEN," December 2012.

Alvaredo, Facundo, Anthony B Atkinson, Thomas Piketty, and Emmanuel Saez, "The top 1 percent in international and historical perspective," The Journal of Economic Perspectives, 2013, 27 (3), 3-20.

Angrist, Joshua D and Miikka Rokkanen, "Wanna get away? Regression discontinuity estimation of exam school effects away from the cutoff," Journal of the American Statistical Association, 2015, 110 (512), 1331-1344.

Arcidiacono, Peter and Michael Lovenheim, "Affirmative action and the quality-fit trade-off," Journal of Economic Literature, 2016, 54 (1), 3-51.

and Sean Nicholson, "Peer effects in medical school," Journal of Public Economics, 2005, 89 (2), 327-350. 
_ Jane Cooley, and Andrew Hussey, "The Economic Returns to an MBA," International Economic Review, 2008, 49 (3), 873-899.

Atkinson, Anthony B, Thomas Piketty, and Emmanuel Saez, "Top incomes in the long run of history," Journal of Economic Literature, 2011, 49 (1), 3-71.

Bertrand, Marianne and Antoinette Schoar, "Managing with style: The effect of managers on firm policies," The Quarterly Journal of Economics, 2003, 118 (4), 1169-1208.

_ Claudia Goldin, and Lawrence F Katz, "Dynamics of the gender gap for young professionals in the financial and corporate sectors," American Economic Journal: Applied Economics, 2010, 2 (3), 228-55.

Björklund, Anders and Markus Jäntti, "Intergenerational income mobility in Sweden compared to the United States," The American Economic Review, 1997, 87 (5), 1009-1018.

Black, Dan A and Jeffrey A Smith, "How robust is the evidence on the effects of college quality? Evidence from matching," Journal of Econometrics, 2004, 121 (1-2), 99-124.

_ and _ _ "Estimating the returns to college quality with multiple proxies for quality," Journal of Labor Economics, 2006, 24 (3), 701-728.

Calonico, Sebastian, Matias D Cattaneo, and Rocio Titiunik, "Robust Nonparametric Confidence Intervals for Regression-Discontinuity Designs," Econometrica, 2014, 82 (6), 22952326.

___ Max H Farrell, and Rocio Titiunik, "Regression discontinuity designs using covariates," Review of Economics and Statistics, 2016, (0).

Cappelli, Peter and Monika Hamori, "The path to the top: Changes in the attributes and careers of corporate executives, 1980-2001," NBER WP 10507, 2004.

Caselli, Francesco and Nicola Gennaioli, "Credit constraints, competition, and meritocracy," Journal of the European Economic Association, 2005, 3 (2-3), 679-689.

and ___ , "Dynastic management," Economic Inquiry, 2013, 51 (1), 971-996.

Cattaneo, Matias D, Rocío Titiunik, Gonzalo Vazquez-Bare, and Luke Keele, "Interpreting regression discontinuity designs with multiple cutoffs," The Journal of Politics, 2016, 78 (4), 1229-1248.

Chetty, Raj, John N Friedman, Emmanuel Saez, Nicholas Turner, and Danny Yagan, "Mobility Report Cards: The Role of Colleges in Intergenerational Mobility," Working Paper 23618, 
National Bureau of Economic Research July 2017.

, Nathaniel Hendren, Patrick Kline, and Emmanuel Saez, "Where is the land of opportunity? The geography of intergenerational mobility in the United States," The Quarterly Journal of Economics, 2014, 129 (4), 1553-1623.

Cossio, Blanco and Fernando Andres, "Distributional effects of tax reform 2014 : Chile," Working Paper 104099, World Bank, Washington, DC 2016.

Dale, S.B. and A.B. Krueger, "Estimating the Payoff to Attending A More Selective College: An Application of Selection on Observables and Unobservables," Quarterly Journal of Economics, 2002, 117 (4), 1491-1527.

Dale, Stacy B and Alan B Krueger, "Estimating the effects of college characteristics over the career using administrative earnings data," Journal of Human Resources, 2014, 49 (2), 323358.

de Chaisemartin, Clément and Luc Behaghel, "Next please! A new definition of the treatment and control groups for randomizations with waiting lists," arXiv preprint arXiv:1511.01453, 2015.

de Giorgi, Giacomo, Michele Pellizzari, and Silvia Redaelli, "Identification of social interactions through partially overlapping peer groups," American Economic Journal: Applied Economics, 2010, pp. 241-275.

Dearden, Lorraine, Stephen Machin, and Howard Reed, "Intergenerational mobility in Britain," The Economic Journal, 1997, pp. 47-66.

Dillon, Eleanor Wiske and Jeffrey Andrew Smith, "Determinants of the match between student ability and college quality," Journal of Labor Economics, 2017, 35 (1), 45-66.

Dobbie, Will and Roland G Fryer, "The impact of attending a school with high-achieving peers: evidence from the New York City exam schools," American Economic Journal: Applied Economics, 2014, 6 (3), 58-75.

Ellison, Glenn and Edward L. Glaeser, "Geographic Concentration in US Manufacturing Industries: A Dartboard Approach," The Journal of Political Economy, 1997, 105 (5), 889-927.

Engel, Eduardo, "Las protestas son repercusiones de la Gran Recesion," Que Pasa, August 1st 2013.

Fairfield, Tasha and Michel Jorratt De Luis, "Top income shares, business profits, and effective tax rates in contemporary Chile," Review of Income and Wealth, 2015. 
Fracassi, Cesare, "Corporate finance policies and social networks," Management Science, 2016, 63 (8), 2420-2438.

and Geoffrey Tate, "External networking and internal firm governance," The Journal of Finance, 2012, 67 (1), 153-194.

Güner, A Burak, Ulrike Malmendier, and Geoffrey Tate, "Financial expertise of directors," Journal of Financial Economics, 2008, 88 (2), 323-354.

Harvard Business School, "Perspectives: Matthew Boys," http://www.hbs.edu/mba/ student-life/people/Pages/perspectives.aspx?profile=mboys 2013. Accessed June 13th 2017.

Hastings, Justine S, Christopher A Neilson, and Seth D Zimmerman, "Are Some Degrees Worth More than Others? Evidence from college admission cutoffs in Chile," Working Paper 19241, National Bureau of Economic Research July 2013.

Hoekstra, Mark, "The Effect of Attending the Flagship State University on Earnings: A Discontinuity-Based Approach," The Review of Economics and Statistics, 2009, 91 (4), 717-724.

Hoxby, Caroline and Christopher Avery, "The missing 'one-offs': The hidden supply of highachieving, low-income students," Brookings Papers on Economic Activity, 2013, 2013 (1), 1-65.

Hsieh, Chang-Tai and Miguel Urquiola, "The effects of generalized school choice on achievement and stratification: Evidence from Chile's voucher program," Journal of Public Economics, 2006, 90 (8), 1477-1503.

Kantor, Jodi, "Class Is Seen as Dividing Harvard Business School," New York Times, September 9th 2013.

Kaufmann, Katja Maria, Matthias Messner, and Alex Solis, "Returns to Elite Higher Education in the Marriage Market: Evidence from Chile," Mimeo, 2013.

Kirkeboen, Lars J, Edwin Leuven, and Magne Mogstad, "Field of study, earnings, and selfselection," The Quarterly Journal of Economics, 2016, 131 (3), 1057-1111.

Lazear, Edward P, Kathryn L Shaw, and Christopher T Stanton, “The value of bosses," Journal of Labor Economics, 2015, 33 (4), 823-861.

Lee, Chul-In and Gary Solon, "Trends in intergenerational income mobility," The Review of Economics and Statistics, 2009, 91 (4), 766-772.

Lee, David S. and Thomas Lemieux, "Regression Discontinuity Designs in Economics," Journal 
of Economic Literature, June 2010, 48 (2), 281-355.

Lewis, Harry R., “The Mission of Harvard College,” February 1997.

Malmendier, Ulrike and Geoffrey Tate, "CEO overconfidence and corporate investment," The Journal of Finance, 2005, 60 (6), 2661-2700.

Marmaros, David and Bruce Sacerdote, "Peer and social networks in job search," European Economic Review, 2002, 46 (4), 870-879.

and __ , "How do friendships form?," The Quarterly Journal of Economics, 2006, 121 (1), 79-119.

Mayer, Adalbert and Steven L. Puller, “The old boy (and girl) network: Social network formation on university campuses," Journal of Public Economics, 2008, 92 (1), 329-347.

McCrary, Justin, "Manipulation of the Running Variable in the Regression Discontinuity Design: A Density Test," Journal of Econometrics, 2008, 142 (2), 698-714.

Miller, William, "American historians and the business elite," The Journal of Economic History, 1949,9 (2), 184-208.

, “The Recruitment of the American Business Elite," The Quarterly Journal of Economics, 1950, pp. 242-253.

Mills, C. Wright, The Power Elite, Oxford University Press, 1956.

Núñez, Javier and Leslie Miranda, "Intergenerational income and educational mobility in urban Chile," Estudios de Economía, 2011, 38 (1), pp-195.

Núñez, Javier I. and Leslie Miranda, "Intergenerational Income Mobility in a Less-Developed, High-Inequality Context: The Case of Chile," The BE Journal of Economic Analysis E Policy, 2010, 10 (1).

Öckert, Björn, "What's the value of an acceptance letter? Using admissions data to estimate the return to college," Economics of Education Review, August 2010, 29 (4), 504-516.

Organization for Economic Cooperation and Development, "Education at a Glance 2012: OECD Indicators," 2012.

Oyer, Paul and Scott Schaefer, "The Returns to Attending a Prestigious Law School," Mimeo, 2009.

Petersen, Mitchell A, "Estimating standard errors in finance panel data sets: Comparing ap- 
proaches," Review of Financial Studies, 2009, 22 (1), 435-480.

Pop-Eleches, Cristian and Miguel Urquiola, "Going to a better school: Effects and behavioral responses," The American Economic Review, 2013, 103 (4), 1289-1324.

Reyes, Loreto, Jorge Rodriguez, and Sergio S. Urzua, "Heterogeneous Economic Returns to Postsecondary Degrees: Evidence from Chile," Journal of Human Resources, 2016, 51 (2), 416460.

Riehl, Evan, Juan E Saavedra, and Miguel Urquiola, "Learning and Earning: An Approximation to College Value Added in Two Dimensions," in "Productivity in Higher Education," University of Chicago Press, 2017.

Rivera, Lauren A, Pedigree: How elite students get elite jobs, Princeton University Press, 2016.

Rolando, Rodrigo, Juan Salamanca, and Marcelo Aliaga, “Evolucion Matricula Educacion Superior de Chile, Periodo 1990-2009," Sistema Nacional de Informacion del Educacion Superior, June 2010.

Rothstein, Jesse and Albert Yoon, "Mismatch in law school," Working Paper no. 14725, National Bureau of Economic Research, Cambridge, MA 2008.

Saavedra, Juan Esteban, "The learning and early labor market effects of college quality: A regression discontinuity analysis," Mimeo, 2009.

Sacerdote, Bruce, "Peer effects with random assignment: Results for Dartmouth roommates," The Quarterly Journal of Economics, 2001, 116 (2), 681-704.

Sander, Richard H, "A systemic analysis of affirmative action in American law schools," Stan. L. Rev., 2004, 57, 367.

Seminarium Penrhyn International, “La Educacion de los Lideres Corporativos,” Technical Report 2003.

Shue, Kelly, "Executive networks and firm policies: Evidence from the random assignment of MBA peers," Review of Financial Studies, 2013, 26 (6), 1401-1442.

Solon, Gary, "Intergenerational income mobility in the United States," The American Economic Review, 1992, pp. 393-408.

Sorokin, Pitirim, "American millionaires and multi-millionaires: A comparative statistical study," Journal of Social Forces, 1925, 3 (4), 627-640. 
Superintendicia de Valores y Seguros (SVS), "Mercado de Valores: Registros," 2013. Accessed June 25th, 2016.

Taussig, Frank William and Carl Smith Joslyn, American Business Leaders: A Study in Social Origins and Social Stratification, Macmillan, 1932.

Temin, Peter, "The American business elite in historical perspective," NBER Historical Paper 104, 1997.

_ _ "The stability of the American business elite," Industrial and Corporate Change, 1999, 8 (2), 189-209.

University of Chicago Booth, "Booth Provides Network And Friendships For Life," https://www.chicagobooth.edu/blog/ewadmissions/2014/ booth-provides-network-and-friendships-for-life 2014. Accessed June 13th 2017.

Urahn, Susan K, Erin Currier, Dana Elliott, Lauren Wechsler, Denise Wilson, and Daniel Colbert, "Pursuing the American dream: Economic mobility across generations," Economic Mobility Project Research Report 2012.

US News and World Report, "Best Global Universities in Latin America," 2016. Accessed June 25th, 2016.

Useem, Michael and Jerome Karabel, "Pathways to top corporate management," American Sociological Review, 1986, pp. 184-200.

Warner, William Lloyd and James C. Abegglen, Occupational mobility in American business and industry, 1928-1952, University of Minnesota Press, 1955.

World Bank, “World Development Indicators," 2016.

Zhang, Hongliang, "The mirage of elite schools: evidence from lottery-based school admissions in China," Mimeo, Chinese University of Hong Kong, 2013.

Zimmerman, Seth D., "The Returns to College Admission for Academically Marginal Students," Journal of Labor Economics, 2014, 32 (4), 711-754. 


\title{
Tables and figures
}

Figure 1: High income shares by educational background
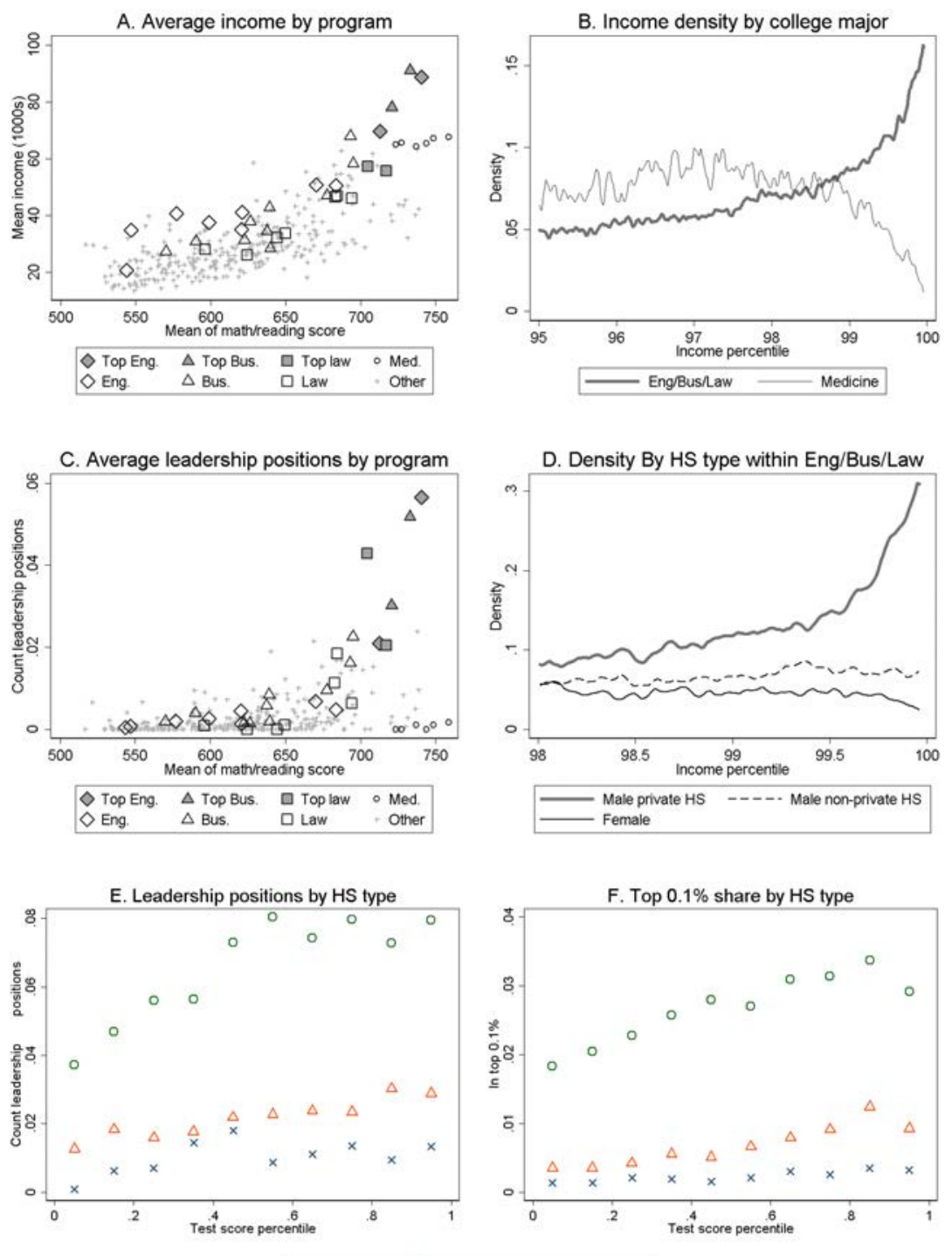

- Male private $\triangle$ Male non-private $\times$ Female

\begin{abstract}
Panel A: mean income by degree program. Each point is a degree program, with marker shapes indicating degree field. Shaded degree programs are the six elite business-focused programs. 'Eng.' abbreviates engineering. 'Med.' is short for medical. Horizontal axis is mean of students' math and reading score. Units: 1000s of 2014 USD. Panel B: Income densities. Horizontal axis is percentile of year-specific income distribution for population of admissions test takers age 30 and over. Vertical axis is density of income distribution for listed majors at PUC and UC. Density computed using Epanechnikov kernel with 0.02 percentile bandwidth. Panel C: Same as panel A but for mean count of leadership positions. Panel D: Density of income by percentile of population income distribution for students admitted to engineering, business, or law programs at UC and PUC, split by gender and HS type. Panels E/F: mean leadership positions (E) and share with top $0.1 \%$ income (F), split by gender and HS type. Horizontal axis is percentile of admissions test distribution for admitted students. Points are means within centered ten percentile bins.
\end{abstract}


Figure 2: Income and top income shares by age and high school type
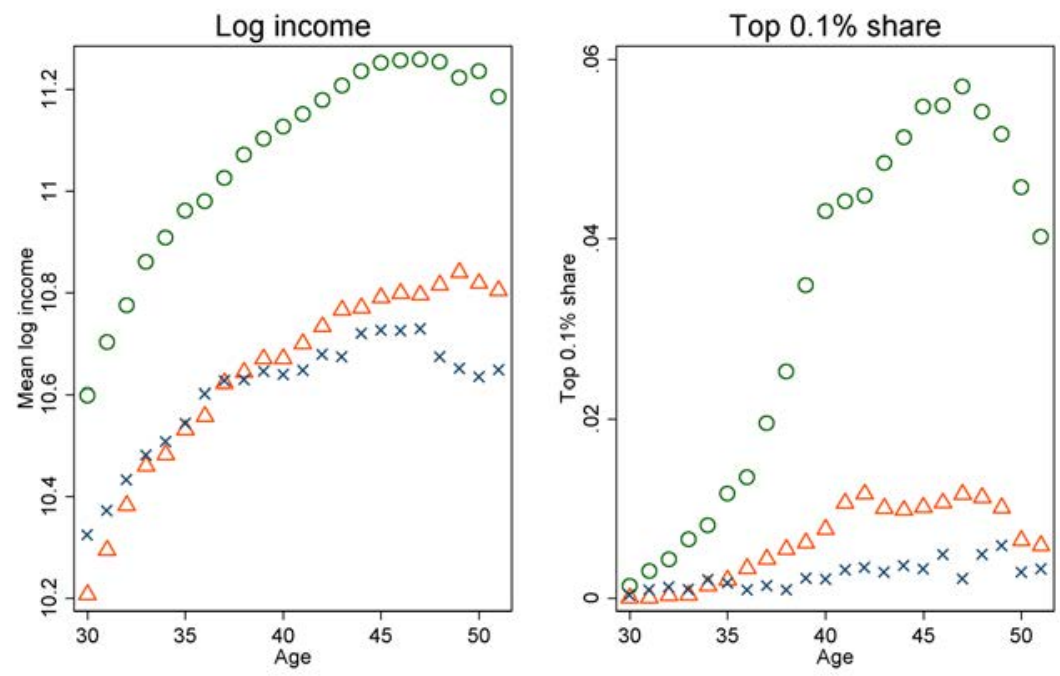

Male private HS $\triangle$ Male non-private HS $\times$ Female

Mean log income and share in top $0.1 \%$ of population income distribution by gender and high school type. Sample is students admitted to UC/PUC programs in Bus/Eng/Law. Earnings measured 2005-2013 for students applying for admission between 1980 and 2001. Horizontal axis is age, calculated based on elapsed time since application, which is assumed to take place at 18 .

Figure 3: Histogram of scores relative to cutoff for elite applications

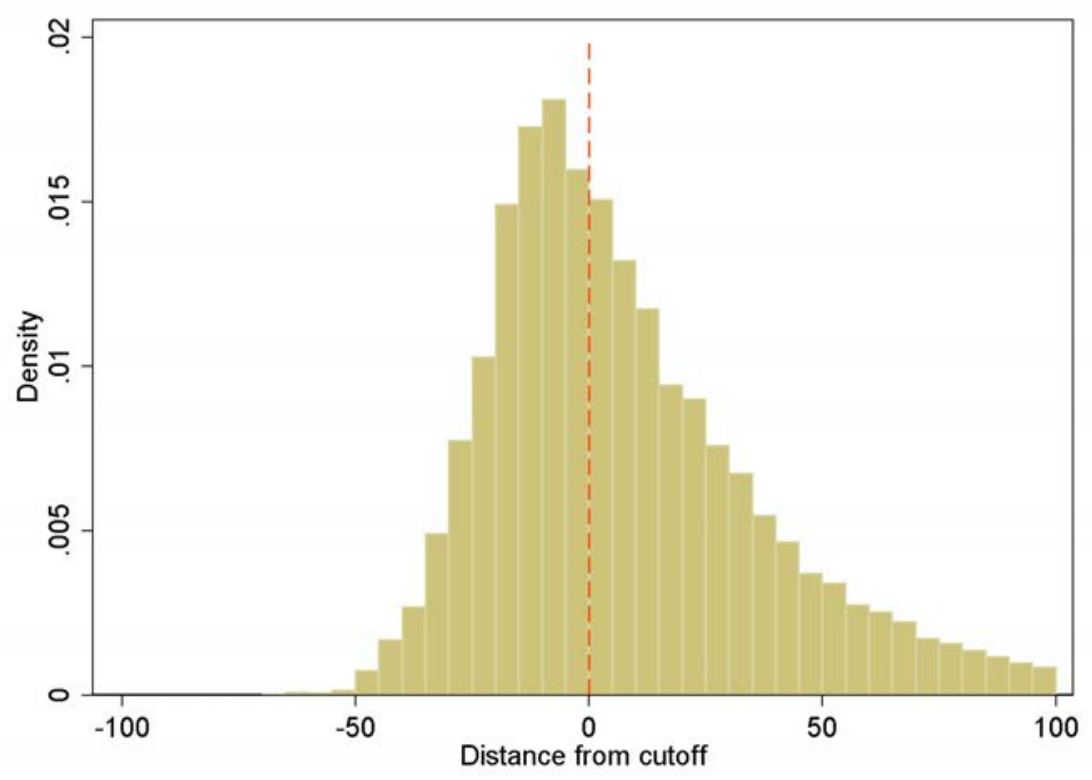

Density of scores for 1974-1991 applicants to elite degree programs. Densities reported within bins of width 5. 
Figure 4: Predetermined covariates by position relative to threshold
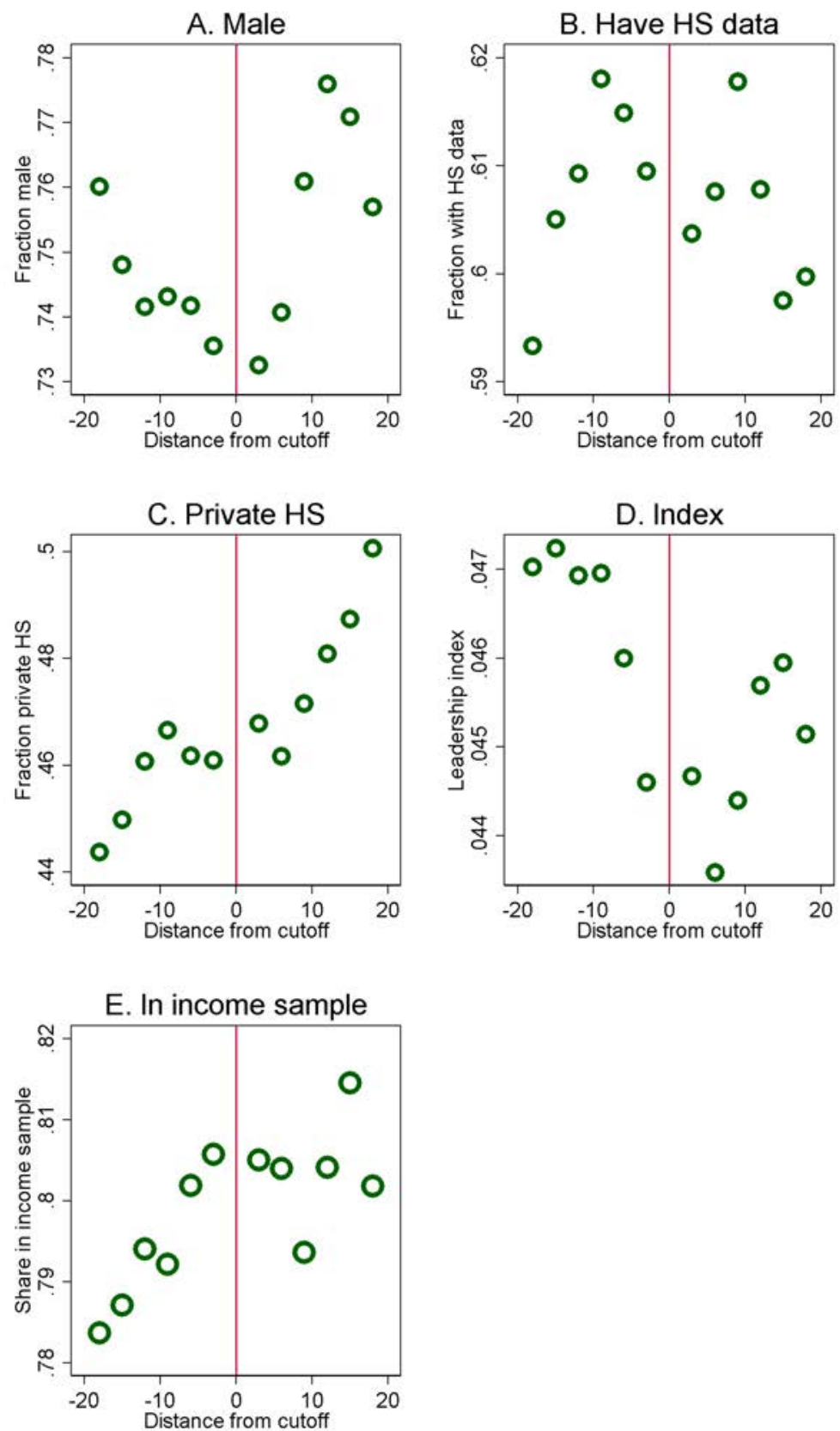

Binned means and fitted values of predetermined covariates by position relative to admissions score threshold. Dependent variables given by panel title. Points reflect average outcomes for applicants within three points on either side of the horizontal axis value. See Figure 3 for distribution of horizontal axis variable. Sample is applicants to elite degree programs. 'Male' is dummy variable equal to one for men and zero otherwise. 'Have HS data' is dummy variable for observations with nonmissing high school data. 'Private HS' is dummy variable for private high school students. 'Index' is the predicted value from a regression of the count of leadership positions on covariates. 'In labor force' is a dummy for presence in the labor force participant sample in a given year (income > roughly \$2,300 USD.) 
Figure 5: Changes in peer characteristics across the admissions threshold
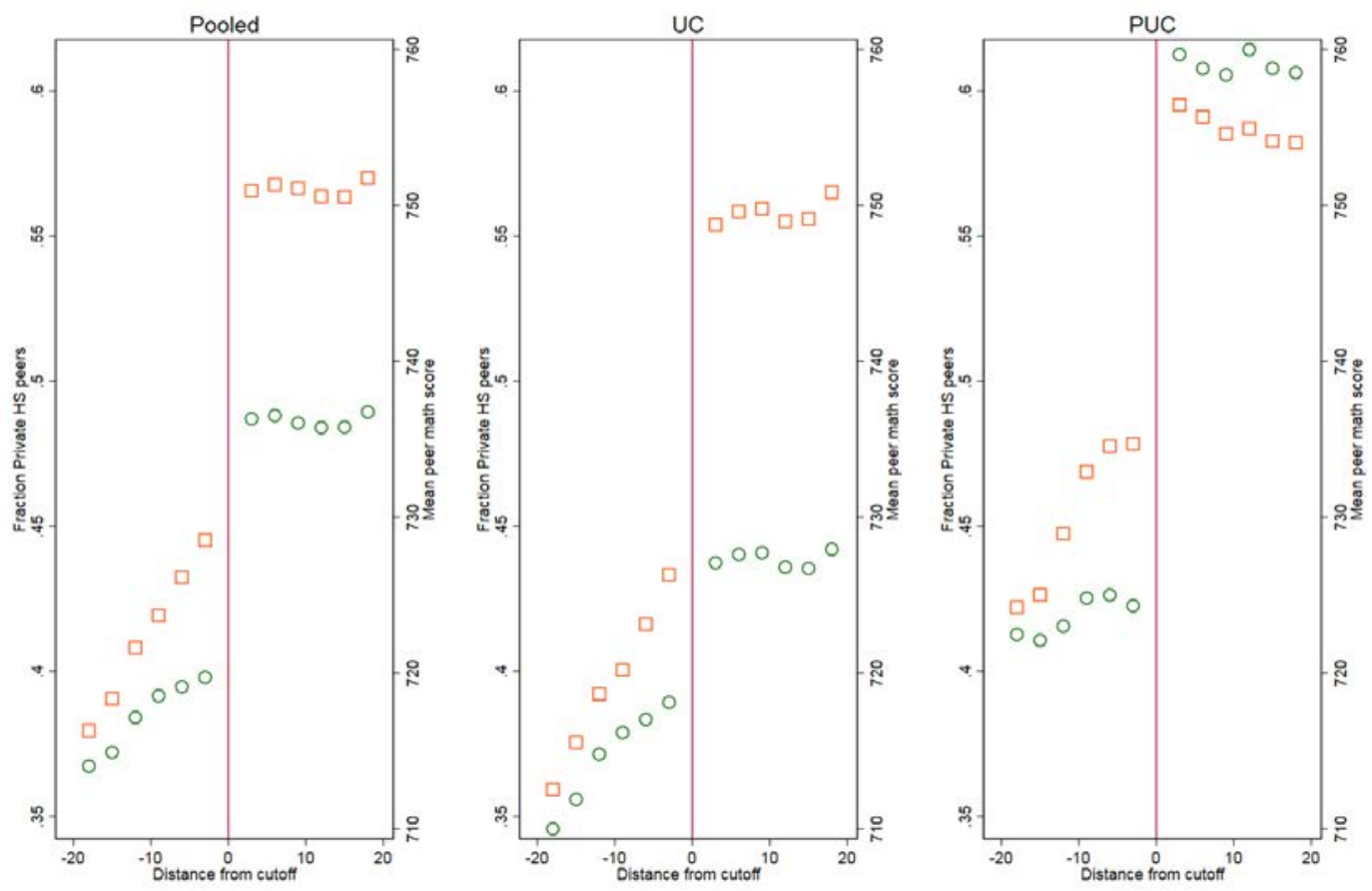

Fraction Private HS peers

Mean peer math score

Fraction of students from private high schools and the mean peer math score at the degree programs to which students are admitted by position relative to admissions score threshold. Peer math scores have mean of 500 and SD of 100 at individual level in the sample of all test takers. Points reflect average values for applicants within three points on either side of the horizontal axis value. See Figure 3 for distribution of horizontal axis variable. Left panel pools across UC and PUC programs. Center and right panel split applications to UC and PUC programs. Left axis is the fraction of private HS peers, right axis is mean peer scores. 
Figure 6: Effect of admission on leadership and top income attainment

\section{A. Top $0.1 \%$ income}
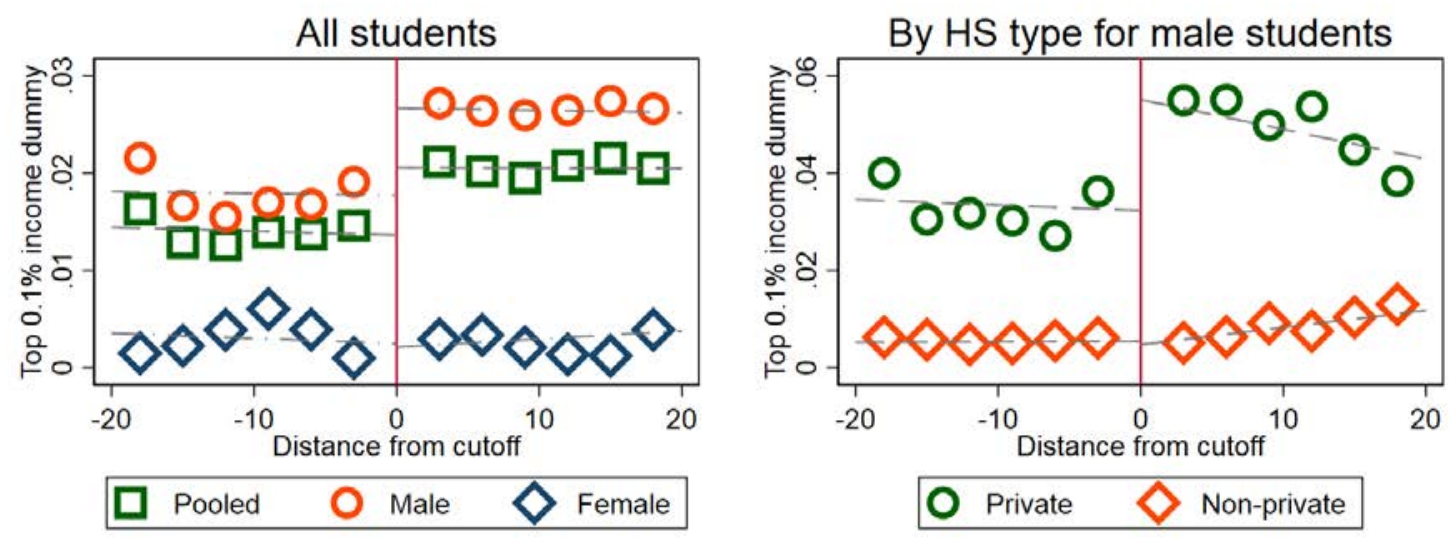

\section{B. Leadership positions}
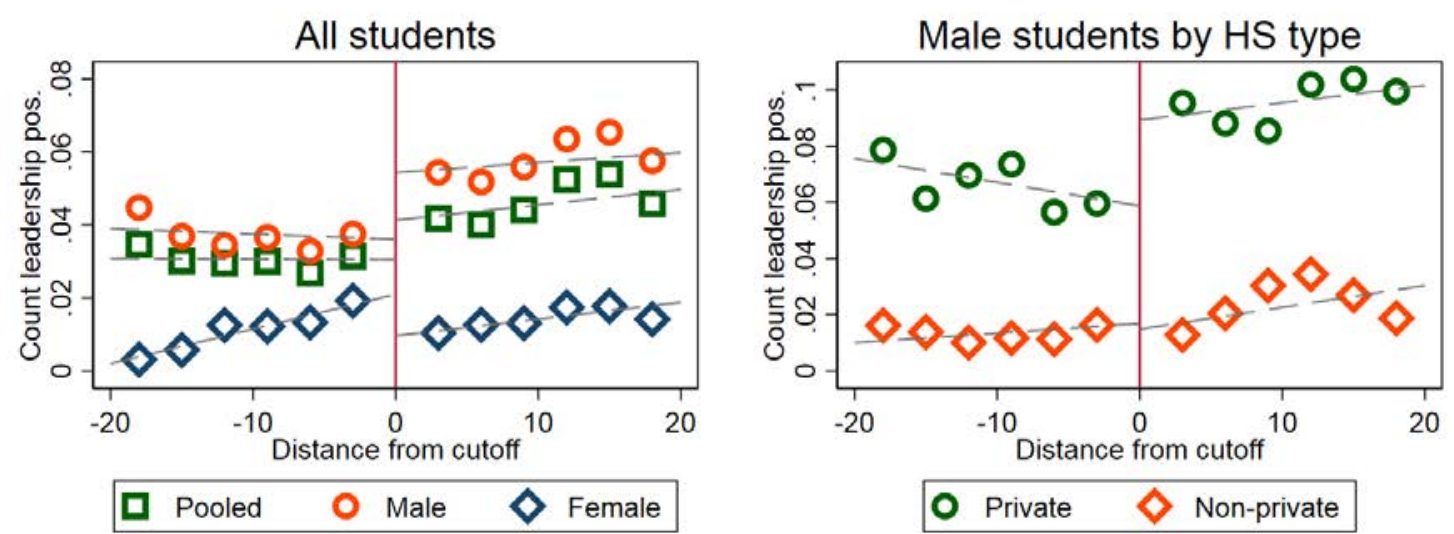

Count of leadership positions and fraction of application-year observations with incomes in the top $0.1 \%$ of the population distribution by position relative to admissions score threshold, gender, and high school type. Graphs pool applications across elite business-focused degree programs. Points reflect average outcomes for applicants within three points on either side of the horizontal axis value. Fitted values from $B W=20$ specification. Negative trend to the left of the cutoff in the lower right panel is statistically insigificant $(\mathrm{p}=0.49)$. It results from changes in the composition of target programs away from the cutoff. There is no evidence of a negative below-threshold slope within program. See Section 4.5 for a discussion. See Figure A-5 for an alternate version of the figure that residualizes on target program and eliminates the slope. 
Figure 7: Admissions effects on alternate high income measures and log income

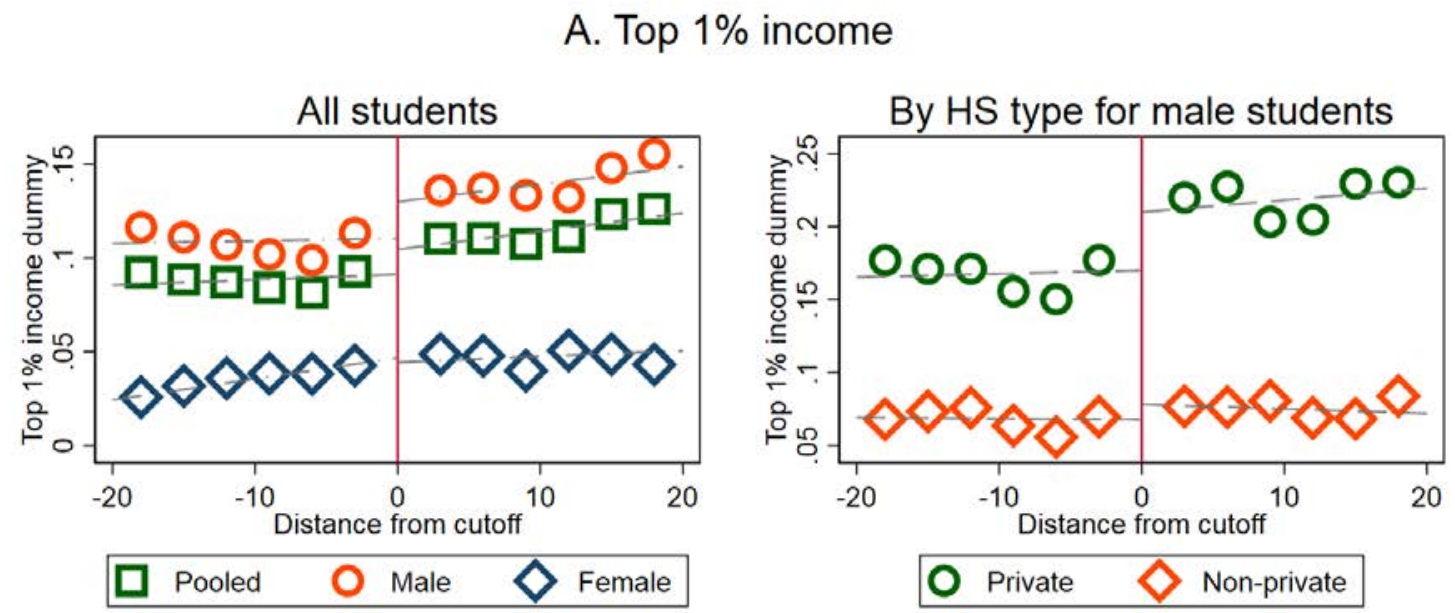

B. Top $10 \%$ income
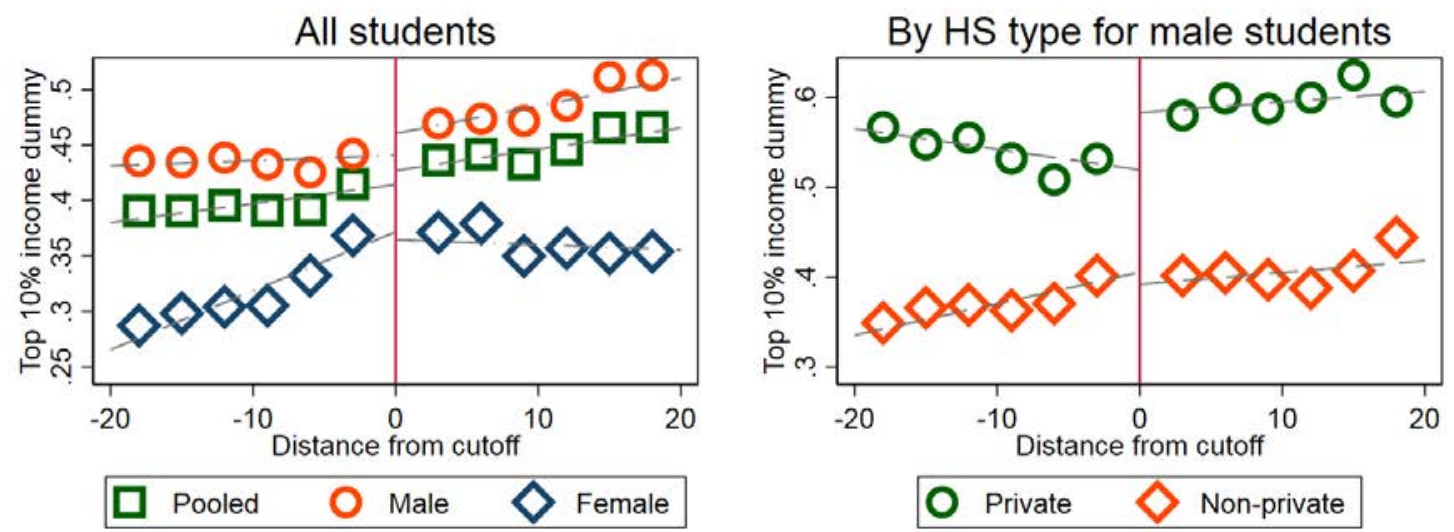

Panels A and B: fraction of application-year observations with incomes in the $1 \%$ and top $10 \%$ incomes by position relative to admissions score threshold, gender, and high school type. Panel C: log income by position relative to threshold. Graphs pool applications across elite degree programs. Points reflect average outcomes for applicants within three points on either side of the horizontal axis value. See Figure 3 for distribution of horizontal axis variable. Fitted values from $B W=20$ specification. 
Figure 7: [Cont'd] Admissions effects on alternate high income measures and log income
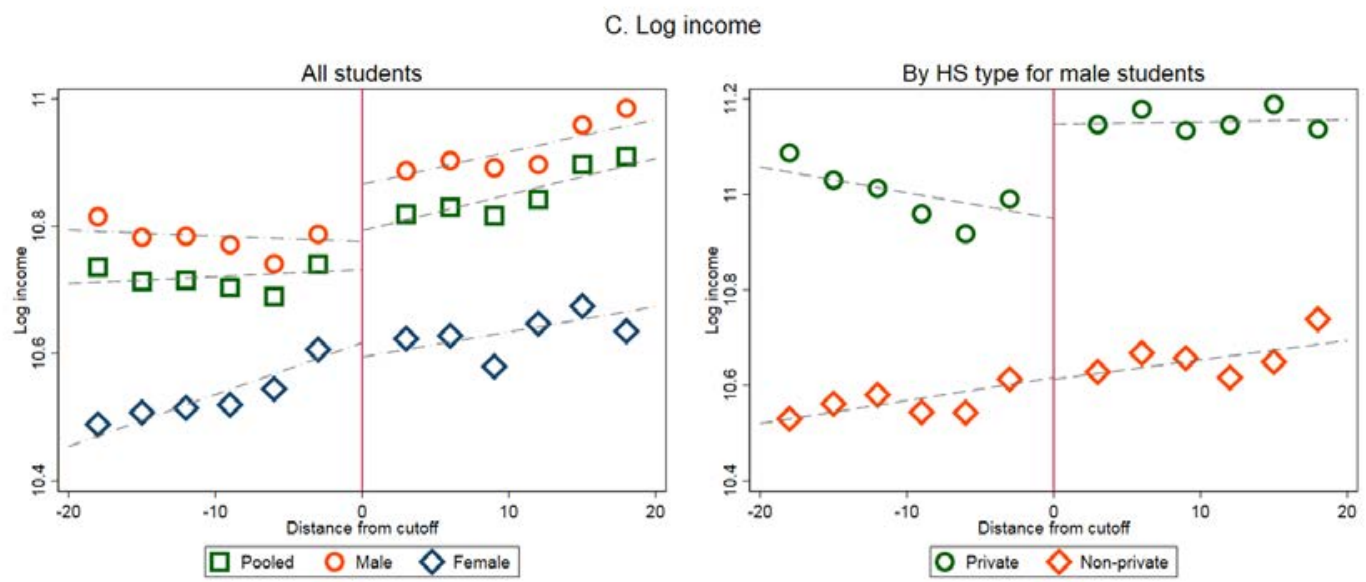

Panels A and B: fraction of application-year observations with incomes in the 1\% and top 10\% incomes by position relative to admissions score threshold, gender, and high school type. Panel C: log income by position relative to threshold. Graphs pool applications across elite degree programs. Points reflect average outcomes for applicants within three points on either side of the horizontal axis value. See Figure 3 for distribution of horizontal axis variable. Fitted values from BW=20 specification. 
Figure 8: Top income attainment by quantile and degree type

\section{A. Top $10 \%$ income attainment in medical degrees}
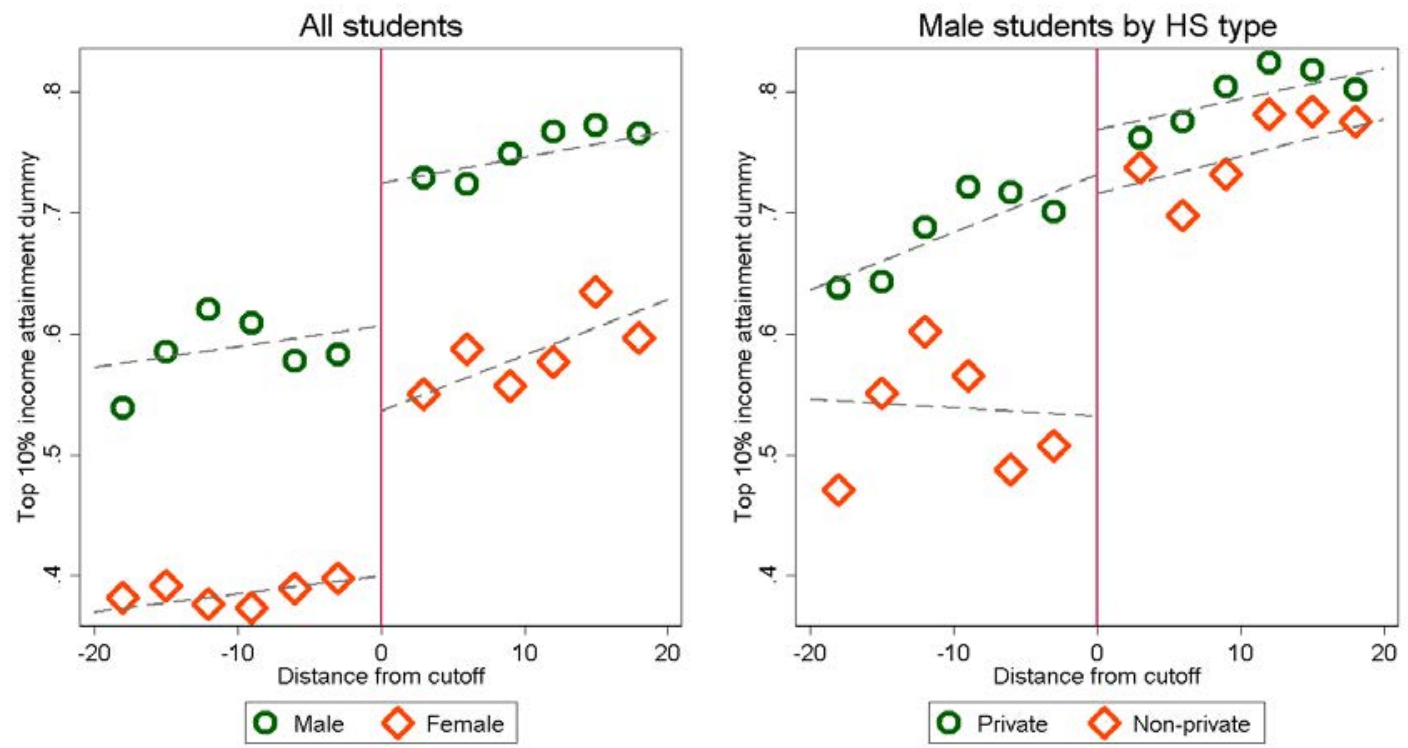

B. Top $0.1 \%$ attainment in medical vs. business degrees
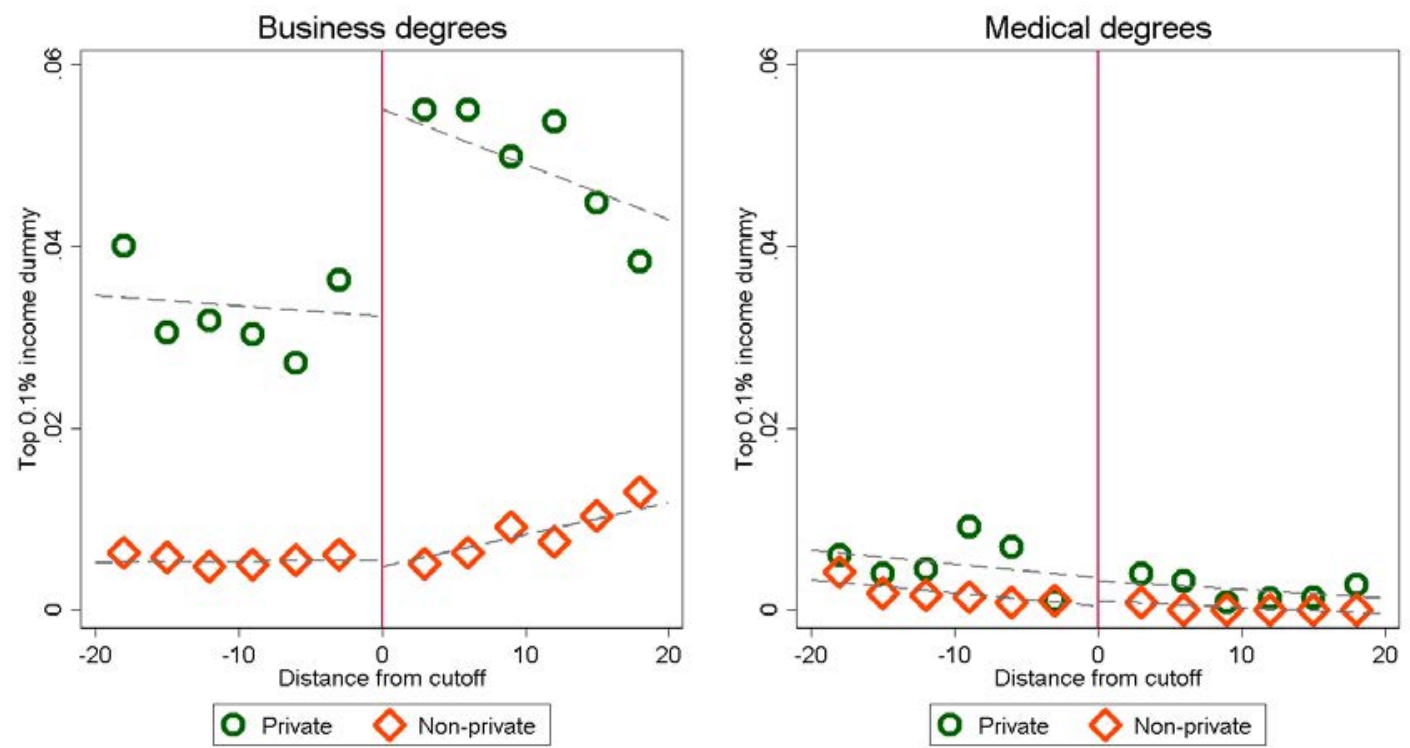

Panel A: fraction of application-year observations with incomes in the top $10 \%$ of the distribution by position relative to admissions score threshold for applicants to medical degrees by gender and HS type. Panel B: fraction of application-year observations with incomes in the top $0.1 \%$ of the distribution among male applicants to business degrees (left panel) and medical degrees (right panel) by position relative to the threshold and high school type. Points are average outcomes for applicants within three points on either side of the horizontal axis value. See Figure 3 for distribution of horizontal axis variable. Fitted values from $\mathrm{BW}=20$ specification. 
Figure 9: Co-leadership rates for private high school students

\title{
A.Co-leadership by cohort distance
}
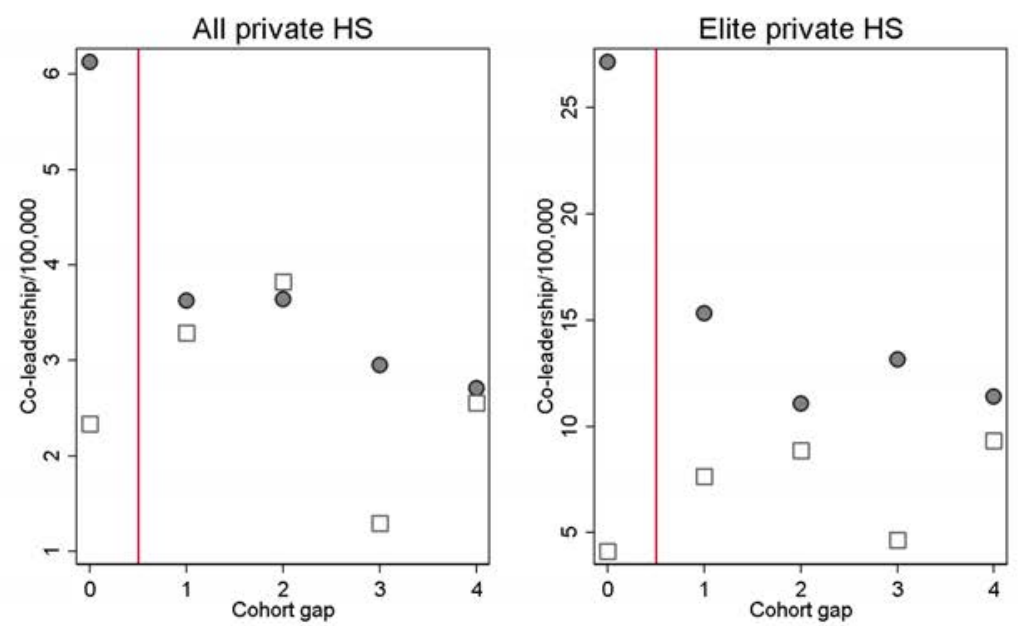

Same program $\square$ Different program, same field

\section{B.Co-leadership by admissions score}
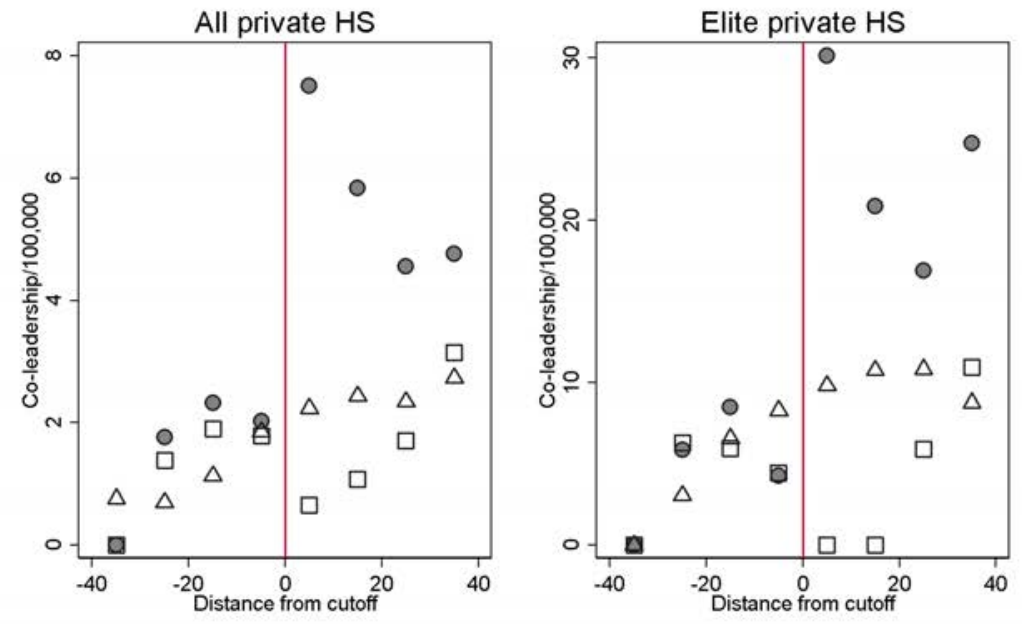

Peers $\triangle$ Same prog, dif year $\square$ Same year, dif prog

\begin{abstract}
Upper panel: rates of co-leadership for male students per 100,000 pairs by absolute difference in application cohort for students in the same field at either the same institution or a different institution. Vertical axis variable is mean over pairs of an indicator that two individuals work at the same firm. Lower panel: Co-leadership rates for pairs of private high school students by position relative to cutoff and peer relationship. Points reflect rolling averages of means within 10 points on either side of the horizontal axis admission score value. 'Peers' points are co-leadership rates with students admitted to the target institution-major in the same cohort as the applicant. 'Same prog, dif year' are co-leadership rates for applicants with students admitted to the same program in another cohort. 'Same year, different prog' presents co-leadership rates for applicants with students admitted to the other elite program in the field in the same cohort.
\end{abstract}


Table 1: Descriptive statistics for test taker and admitted students samples

\begin{tabular}{lcccccc} 
& All test takers & Elite admits & Male private HS & Male non-private HS & Female & All admitted \\
\hline Reading & 485 & 675 & 686 & 662 & 678 & 578 \\
Math & 481 & 738 & 752 & 730 & 725 & 601 \\
Elite degree & 0.018 & 1.000 & 1.000 & 1.000 & 1.000 & 0.058 \\
Have HS & & 0.790 & 1.000 & 1.000 & 0.768 & 0.866 \\
Private HS & & 0.598 & 1.000 & 0.000 & 0.631 & 0.270 \\
Any leadership pos. & 0.001 & 0.026 & 0.042 & 0.012 & 0.009 & 0.003 \\
Count leadership pos. & 0.002 & 0.041 & 0.068 & 0.020 & 0.010 & 0.004 \\
N individuals & 1957450 & 36211 & 12075 & 8530 & 9446 & 579088 \\
& & & & 0.850 & 0.834 & 0.799 \\
In LF sample & 0.680 & 0.851 & 0.874 & 60.6 & 54.2 & 32.7 \\
Mean income (1000s USD) & 23.1 & 73.8 & 92.0 & 0.462 & 0.430 & 0.178 \\
Top 10\% & 0.100 & 0.542 & 0.631 & 0.282 & 0.241 & 0.091 \\
Top 5\% & 0.050 & 0.356 & 0.449 & 0.073 & 0.043 & 0.018 \\
Top 1\% & 0.010 & 0.112 & 0.171 & 0.036 & 0.019 & 0.009 \\
Top 0.5\% & 0.005 & 0.065 & 0.108 & 0.007 & 0.003 & 0.002 \\
Top 0.1\% & 0.001 & 0.016 & 0.031 & 53684 & 54906 & 3144037 \\
N person-years & 9338198 & 223762 & 69009 & & & \\
\hline
\end{tabular}

Descriptions of student characteristics, leadership outcomes, and income distributions. Upper panel reports observations at individual level. Lower panel reports observations at individual-outcome year level for outcome years at least twelve years after the application year, or roughly age 30. Outcome years range from 2005 to 2013 . Cells are means of row variables unless otherwise specificied. Columns: 'Test-takers' includes all admissions test takers over the 1980-2001 period. 'Elite admits' includes students admitted to one of six elite business-focused programs. 'Male private HS' is male students identified as coming from private school backgrounds who are admitted to elite degree programs. 'Male non-private HS' is elite admits who do not attend private schools. 'Female' is female students admitted to elite schools, regardless of HS type. 'All admitted' includes all students admitted to any program between 1982 and 2001. Rows: 'reading' and 'math' are students' admissions exam scores from their first test attempt. 'Elite admit' is a dummy equal to one if a student is admitted to one of the six elite degree programs. 'Have HS' identifies students matched to high school types; 'Private HS' identifies the set of matched students who attended private high schools. 'Any leadership position' is the mean of an indicator equal to one if a student has some directorship or C-suite position; 'count of positions' is the mean count of positions held. 'In LF sample' is a dummy equal to one for students who match to the labor force dataset. 'Mean income' is in 1000s of 2014 USD. Categorical percentile variables are means of dummies equal to one if a student's income an outcome year falls within the indicated percentile range. 
Table 2: Regression discontinuity sample description

\begin{tabular}{lcccc} 
& All & Marginal & Male marginal & Male marginal w/HS \\
\hline A. 1980-1991 & & & & \\
Male & 0.76 & 0.74 & 1.00 & 1.00 \\
Age & 43.9 & 44.0 & 44.0 & 44.1 \\
Reading & 658 & 655 & 653 & 654 \\
Math & 742 & 735 & 738 & 740 \\
Have HS data & 0.72 & 0.72 & 0.75 & 1.00 \\
Private HS & & & & 0.482 \\
In LF sample & 0.804 & 0.798 & 0.825 & 0.858 \\
Average earnings & 80.8 & 78.3 & 85.3 & 86.1 \\
Top 0.1\% share & 0.018 & 0.017 & 0.021 & 0.021 \\
N application years & 235909 & 139719 & 98935 & 74167 \\
N applicants & 29987 & 18224 & 12786 & 8735 \\
& & & & \\
B. 1974-1991 & & & & 1.00 \\
Male & 0.77 & 0.75 & 1.00 & 48.2 \\
Age & 48.3 & 48.3 & 48.4 & 656 \\
Reading & 661 & 658 & 655 & 738 \\
Math & 741 & 733 & 736 & 0.464 \\
Have HS data & 0.600 & 0.607 & 0.637 & 0.029 \\
Private HS & & & & 0.051 \\
Any leadership position & 0.029 & 0.024 & 0.030 & 0.002 \\
Count leadership positions & 0.049 & 0.041 & 0.051 & 0.031 \\
> 4 positions & 0.002 & 0.001 & 0.002 & 0.020 \\
Count BOD & 0.031 & 0.026 & 0.033 & 15286 \\
Count C-suite & 0.018 & 0.015 & 0.018 & 11478 \\
N applications & 57940 & 33624 & 24009 & \\
N applicants & 43845 & 25950 & 18439 & \\
\hline
\end{tabular}

Description of sample means and counts. Upper panel describes sample used in estimation of earnings specifications. Observations are at application-outcome year level for outcome years 2005-2013 and application years 1980-1991. Only application-year outcome-year pairs in which students are age 40 or older are included in the sample. Lower panel describes the sample used in leadership specifications, and includes 1974-1991 applications to elite degree programs. Observations at application level. 'All' is full sample of applicants observed in data. 'Marginal' restricts sample to students within 20 points on either side of admissions threshold. 'Male marginal' is sample of marginal male applicants. 'Male marginal w/ HS' subsets on marginal male students for whom high school can be classified as private or non-private. 'Reading' and 'Math' are student scores on admissions tests. 'Private HS' is a dummy equal to one if students attended a private high school. 'In LF sample' is a dummy equal to one if an application-year record is matched to the labor force sample. Earnings measured in 2014 USD. 'Top $0.1 \%$ share' is a dummy equal to one if students have an income record in top $0.1 \%$ of the income distribution. 'Any leadership position' is a dummy equal to one if student holds at least one C-suite or directorship position. 'Count leadership positions,' 'count BOD', and 'count C-suite' are mean of the total number of positions, directorships, and C-suite positions students hold. ' $>4$ positions' is and indicator variable equal to one if a student holds more than four leadership positions. 
Table 3: Balance on predetermined covariates

\begin{tabular}{|c|c|c|c|c|}
\hline & All & Male & Private & Non-private \\
\hline \multicolumn{5}{|l|}{ A. $B W=10$} \\
\hline Male & $\begin{array}{c}0.0014 \\
(0.0066)\end{array}$ & & & \\
\hline Have HS & $\begin{array}{l}-0.0058 \\
(0.0072)\end{array}$ & $\begin{array}{c}-0.0047 \\
(0.0084)\end{array}$ & & \\
\hline Private HS & $\begin{array}{c}0.0087 \\
(0.0094)\end{array}$ & $\begin{array}{c}0.0071 \\
(0.0109)\end{array}$ & & \\
\hline Index & $\begin{array}{l}-0.0006 \\
(0.0007)\end{array}$ & $\begin{array}{l}-0.0006 \\
(0.0007)\end{array}$ & $\begin{array}{c}-0.0006 \\
(0.0010)\end{array}$ & $\begin{array}{c}-0.0007 \\
(0.0008)\end{array}$ \\
\hline $\mathrm{N}$ & 18266 & 12933 & 3853 & 4462 \\
\hline In LF sample & $\begin{array}{c}0.0044 \\
(0.0071)\end{array}$ & $\begin{array}{c}0.0027 \\
(0.0080)\end{array}$ & $\begin{array}{c}0.0013 \\
(0.0109)\end{array}$ & $\begin{array}{c}0.0077 \\
(0.0119)\end{array}$ \\
\hline Intercept & 0.797 & 0.823 & 0.872 & 0.838 \\
\hline $\mathrm{N}$ & 77045 & 54134 & 19507 & 21412 \\
\hline \multicolumn{5}{|l|}{ B. $B W=20$} \\
\hline Male & $\begin{array}{c}0.0030 \\
(0.0095)\end{array}$ & & & \\
\hline Have HS & $\begin{array}{l}-0.0108 \\
(0.0103)\end{array}$ & $\begin{array}{l}-0.0162 \\
(0.0121)\end{array}$ & & \\
\hline Private HS & $\begin{array}{l}-0.0071 \\
(0.0136)\end{array}$ & $\begin{array}{c}-0.0089 \\
(0.0158)\end{array}$ & & \\
\hline Index & $\begin{array}{c}0.0007 \\
(0.0009)\end{array}$ & $\begin{array}{c}0.0006 \\
(0.0010)\end{array}$ & $\begin{array}{c}0.0013 \\
(0.0015)\end{array}$ & $\begin{array}{c}0.0013 \\
(0.0012)\end{array}$ \\
\hline $\mathrm{N}$ & 33624 & 24009 & 7096 & 8190 \\
\hline In LF sample & $\begin{array}{l}-0.0024 \\
(0.0103)\end{array}$ & $\begin{array}{c}-0.0038 \\
(0.0116)\end{array}$ & $\begin{array}{c}0.0027 \\
(0.0155)\end{array}$ & $\begin{array}{l}-0.0010 \\
(0.0164)\end{array}$ \\
\hline Intercept & 0.805 & 0.831 & 0.874 & 0.847 \\
\hline $\mathrm{N}$ & 139719 & 98935 & 35733 & 38434 \\
\hline
\end{tabular}

Standard errors in parentheses. Estimates of equations 1 and 2 where dependent variables are predetermined covariates (Panel A) and labor force participation (Panel B). Left three columns are BW=10 specification, right three columns are BW=20 specification. See section 4.1 for a description of these specifications. 'All' column includes all applications. 'Male' column is male students only. 'Private' and 'Non-private' columns report separate estimates by high school type for male students. Observations in Panel A are at the application level. 'Have HS' is an indicator equal to one if an applicant's high school can be classified. 'Index' is a linear, leadership-weighted index of application cohort and target degree program fixed effects. p-values from a joint test that effects of admission on gender, the dummy for high school type data, and high school type are equal to zero are 0.66 in the $B W=10$ specification and 0.67 in the $\mathrm{BW}=20$ specification. Observations in Panel B are at the application-outcome year level. 'In LF' is a dummy equal to one if a student is matched to the labor force sample in a given application-year. Standard errors cluster at person level. 
Table 4: Effect of elite admission on peer attributes and other acceptance outcomes

\begin{tabular}{|c|c|c|c|c|c|}
\hline & \multicolumn{2}{|c|}{ Effects on peer attributes } & \multicolumn{3}{|c|}{ Below threshold acceptance outcomes } \\
\hline & Peer elite HS & Peer math & $\begin{array}{l}\text { Same field, } \\
\text { other elite }\end{array}$ & $\begin{array}{c}\text { Same field } \\
\text { non-elite }\end{array}$ & $\begin{array}{l}\text { Any bus. } \\
\text { field }\end{array}$ \\
\hline \multicolumn{6}{|l|}{ A. Pooled } \\
\hline Main effect & $\begin{array}{c}0.091 \\
(0.003)\end{array}$ & $\begin{array}{l}24.129 \\
(0.626)\end{array}$ & $\begin{array}{c}0.124 \\
(0.005)\end{array}$ & $\begin{array}{c}0.460 \\
(0.007)\end{array}$ & $\begin{array}{c}0.666 \\
(0.007)\end{array}$ \\
\hline $\mathrm{N}$ & 8605 & 8659 & 9100 & 9100 & 9100 \\
\hline \multicolumn{6}{|l|}{ B. By institution } \\
\hline $\mathrm{UC}$ & $\begin{array}{c}0.053 \\
(0.003)\end{array}$ & $\begin{array}{l}24.756 \\
(0.611)\end{array}$ & $\begin{array}{c}0.002 \\
(0.001)\end{array}$ & $\begin{array}{c}0.572 \\
(0.008)\end{array}$ & $\begin{array}{c}0.663 \\
(0.008)\end{array}$ \\
\hline $\mathrm{N}$ & 6259 & 6290 & 6629 & 6629 & 6629 \\
\hline PUC & $\begin{array}{c}0.184 \\
(0.007)\end{array}$ & $\begin{array}{l}21.864 \\
(1.568)\end{array}$ & $\begin{array}{c}0.468 \\
(0.014)\end{array}$ & $\begin{array}{c}0.145 \\
(0.010)\end{array}$ & $\begin{array}{c}0.675 \\
(0.013)\end{array}$ \\
\hline $\mathrm{N}$ & 2346 & 2369 & 2471 & 2471 & 2471 \\
\hline \multicolumn{6}{|l|}{ C. Interactions } \\
\hline Main effect & $\begin{array}{c}0.074 \\
(0.006)\end{array}$ & $\begin{array}{l}22.806 \\
(1.381)\end{array}$ & $\begin{array}{c}0.120 \\
(0.009)\end{array}$ & $\begin{array}{c}0.346 \\
(0.013)\end{array}$ & $\begin{array}{c}0.543 \\
(0.014)\end{array}$ \\
\hline Interaction with Male & $\begin{array}{c}0.024 \\
(0.007)\end{array}$ & $\begin{array}{c}1.784 \\
(1.531)\end{array}$ & $\begin{array}{c}0.004 \\
(0.010)\end{array}$ & $\begin{array}{c}0.164 \\
(0.016)\end{array}$ & $\begin{array}{c}0.177 \\
(0.016)\end{array}$ \\
\hline $\begin{array}{l}\mathrm{N} \\
\text { Private HS }\end{array}$ & 8467 & 8520 & 8954 & 8954 & 8954 \\
\hline Main effect & $\begin{array}{c}0.107 \\
(0.005)\end{array}$ & $\begin{array}{l}27.237 \\
(1.107)\end{array}$ & $\begin{array}{c}0.060 \\
(0.007)\end{array}$ & $\begin{array}{c}0.543 \\
(0.014)\end{array}$ & $\begin{array}{c}0.687 \\
(0.014)\end{array}$ \\
\hline Interaction with Private HS & $\begin{array}{l}-0.019 \\
(0.008)\end{array}$ & $\begin{array}{l}-4.066 \\
(1.543)\end{array}$ & $\begin{array}{c}0.089 \\
(0.013)\end{array}$ & $\begin{array}{l}-0.070 \\
(0.021)\end{array}$ & $\begin{array}{c}0.028 \\
(0.020)\end{array}$ \\
\hline $\mathrm{N}$ & 3972 & 3972 & 4193 & 4193 & 4193 \\
\hline
\end{tabular}

Standard errors in parentheses. Effects of admissions-threshold crossing on peer attributes (left two columns) and description of below-threshold admissions outcomes (right three columns). Panel A presents findings pooling over student demographics and programs. 'Main effect' is the effect of admission (left two columns) or below-threshold outcome (right three columns). Panel B splits by institution, as noted. Panel C allows for interactions between student demographics and admissions effects/below threshold outcomes. The 'Male' specifications allow for gender interactions in the full dataset. The 'Private HS' specifications subset on male students. Observations include the application years 1982 through 1991. These are the years for which applications to both elite degree programs and the broader set of CRUCH programs are available. See Online Appendix B.1. Estimates obained using BW=10 specification. Left two columns: admissions effects where dependent variable is the listed peer attribute. Panels A and B report admissions effects for all students in listed institution. Panel $\mathrm{C}$ reports main admissions effect (in 'main effect' row) and interaction with listed characteristic (in 'interaction' row). Right three columns: Panels A and B report fractions of marginally rejected students admitted to degrees of the type listed in the column. Panel C reports intercept term main effects and interactions with the listed covariate. Standard errors cluster at individual level. 
Table 5: Effect of elite admission on top income and leadership outcomes

\begin{tabular}{|c|c|c|c|c|c|}
\hline & \multicolumn{2}{|c|}{ Top outcomes } & \multicolumn{3}{|c|}{ Additional measures } \\
\hline & Top $0.1 \%$ & Leadership & Top $1 \%$ & Top $10 \%$ & Log inc. \\
\hline \multicolumn{6}{|l|}{ A. $B W=10$} \\
\hline \multirow[t]{3}{*}{ All } & 0.007 & 0.013 & 0.021 & 0.033 & 0.100 \\
\hline & $(0.002)$ & $(0.004)$ & $(0.005)$ & $(0.009)$ & $(0.020)$ \\
\hline & 77045 & 18266 & 77045 & 77045 & 61572 \\
\hline \multirow[t]{3}{*}{ Male } & 0.009 & 0.019 & 0.027 & 0.036 & 0.121 \\
\hline & $(0.003)$ & (0.006) & $(0.007)$ & (0.010) & $(0.024)$ \\
\hline & 54134 & 12933 & 54134 & 54134 & 44646 \\
\hline \multirow[t]{3}{*}{ Female } & 0.000 & -0.005 & 0.006 & 0.020 & 0.030 \\
\hline & $(0.001)$ & $(0.005)$ & $(0.006)$ & $(0.016)$ & $(0.035)$ \\
\hline & 19581 & 4548 & 19581 & 19581 & 15271 \\
\hline Test & 0.005 & 0.001 & 0.028 & 0.399 & 0.031 \\
\hline \multirow[t]{3}{*}{ Male private } & 0.022 & 0.032 & 0.054 & 0.065 & 0.203 \\
\hline & $(0.007)$ & $(0.014)$ & $(0.013)$ & $(0.017)$ & $(0.039)$ \\
\hline & 19507 & 3853 & 19507 & 19507 & 17020 \\
\hline \multirow[t]{3}{*}{ Male non-private } & 0.001 & 0.002 & 0.008 & 0.015 & 0.056 \\
\hline & $(0.002)$ & $(0.005)$ & $(0.008)$ & $(0.017)$ & $(0.036)$ \\
\hline & 21412 & 4462 & 21412 & 21412 & 18018 \\
\hline Test & 0.003 & 0.039 & 0.003 & 0.036 & 0.006 \\
\hline \multicolumn{6}{|l|}{ B. $B W=20$} \\
\hline \multirow[t]{2}{*}{ All } & 0.007 & 0.011 & 0.013 & 0.013 & 0.061 \\
\hline & $\begin{array}{l}(0.003) \\
139719\end{array}$ & $\begin{array}{l}(0.006) \\
33624\end{array}$ & $\begin{array}{l}(0.008) \\
139719\end{array}$ & $\begin{array}{l}(0.012) \\
139719\end{array}$ & $\begin{array}{l}(0.029) \\
111501\end{array}$ \\
\hline \multirow[t]{3}{*}{ Male } & 0.009 & 0.018 & 0.020 & 0.020 & 0.090 \\
\hline & $(0.004)$ & $(0.008)$ & $(0.010)$ & $(0.015)$ & $(0.035)$ \\
\hline & 98935 & 24009 & 98935 & 98935 & 81663 \\
\hline \multirow[t]{3}{*}{ Female } & -0.000 & -0.011 & -0.002 & -0.007 & -0.022 \\
\hline & $(0.002)$ & (0.007) & $(0.010)$ & (0.023) & $(0.050)$ \\
\hline & 34775 & 8119 & 34775 & 34775 & 26917 \\
\hline Test & 0.054 & 0.005 & 0.108 & 0.330 & 0.063 \\
\hline \multirow[t]{3}{*}{ Male private } & 0.023 & 0.031 & 0.040 & 0.064 & 0.198 \\
\hline & $(0.010)$ & $(0.020)$ & $(0.020)$ & $(0.025)$ & $(0.058)$ \\
\hline & 35733 & 7096 & 35733 & 35733 & 31262 \\
\hline \multirow[t]{3}{*}{ Male non-private } & -0.001 & -0.002 & 0.010 & -0.013 & -0.003 \\
\hline & $(0.003)$ & $(0.007)$ & $(0.012)$ & $(0.024)$ & $(0.051)$ \\
\hline & 38434 & 8190 & 38434 & 38434 & 32405 \\
\hline Test & 0.028 & 0.119 & 0.203 & 0.024 & 0.009 \\
\hline
\end{tabular}

Standard errors in parentheses, $\mathrm{N}$ in lowest row of each cell. Estimates of effects of admission on leadership and top income attainment by gender and by high school type for male students. Panel A reports estimates from BW=10 specification and Panel B from BW=20 specification. Columns denote dependent variables. 'Leadership' is count of leadership positions. Observations in the top income and log income columns are at application-outcome year level, while observations in leadership column are at the application level. Top income indicators are zero for labor force non-participants. 'Test' rows report p-values from tests that effects for male and female students (upper) and private and non-private high school students are equal. Standard errors clustered at person level. 
Table 6: Heterogeneous effects by high school type and other student characteristics

\begin{tabular}{lcccc} 
& Private HS & Math & Verbal & Santiago \\
\hline A. Descriptive statistics & & & & \\
Private & & 744 & 658 & 0.819 \\
Non-private & & 736 & 653 & 0.698 \\
Gap & & 4.5 & 4.8 & 0.120 \\
Adjusted gap & & & & \\
& & & & \\
B. Admissions effect estimates & & 0.7 & 0.114 \\
Top 0.1\% & $(0.0073)$ & $(0.0006)$ & $(0.0005)$ & $(0.0068)$ \\
& & & & \\
& 0.0285 & 0.0019 & 0.0011 & 0.0014 \\
Leadership & $(0.0157)$ & $(0.0015)$ & $(0.0013)$ & $(0.0129)$ \\
& & & & \\
Log income & 0.1646 & 0.0035 & -0.0006 & -0.0980 \\
& $(0.0538)$ & $(0.0060)$ & $(0.0042)$ & $(0.0634)$ \\
& & & & \\
C. Santiago only & & & & \\
Top 0.1\% & 0.0235 & & & \\
& $(0.0087)$ & & & \\
Leadership & & & & \\
Log income & 0.0277 & & & \\
& $(0.0170)$ & & & \\
\hline
\end{tabular}

Panel A: Differences in variable listed in column by high school type within BW=10 sample of male marginal applicants. 'Non-private' and 'private' rows are means by high school type. 'Gap' is the difference in means for each high school type. 'Adjusted gap' is mean difference within cells defined by target program and application year. Panel B: Estimates of interaction effects from BW=10 RD specification that allows for interactions between admission and each listed variable in columns. Standard errors in parentheses. Dependent variables are listed in rows. Each specification includes a main effect of admission, an intercept term, and controls for main effects of the column variables. Panel B sample: 1980-1991 marginal applications from male students with non-missing test score and geographic data. 19741979 application years omitted from leadership specifications due to unavailability of test score data. Panel C sample: all pre-1991 marginal applications with available geographic data. Panel A sample size: 7055 individuals (Math, Verbal); 7245 (Santiago). Panel B sample sizes: 39,296 for top income, 33,853 for log income, 5,934 for leadership. Panel C sample sizes: 29,755 for top income, 25,815 for log income, 6,496 for leadership. 
Table 7: Effect of admission on sector of employment

\begin{tabular}{|c|c|c|c|c|c|c|}
\hline \multirow[b]{2}{*}{ Name } & \multicolumn{2}{|c|}{ All } & \multicolumn{2}{|c|}{ Private HS } & \multicolumn{2}{|c|}{ Non-private HS } \\
\hline & BL & Effect & BL & Effect & BL & Effect \\
\hline Real estate/rental/business activities & 0.169 & $\begin{array}{c}0.005 \\
(0.008)\end{array}$ & 0.163 & $\begin{array}{c}0.020 \\
(0.014)\end{array}$ & 0.163 & $\begin{array}{c}0.008 \\
(0.013)\end{array}$ \\
\hline Wholesale/retail trade & 0.158 & $\begin{array}{c}0.000 \\
(0.009)\end{array}$ & 0.164 & $\begin{array}{c}0.011 \\
(0.014)\end{array}$ & 0.149 & $\begin{array}{c}-0.008 \\
(0.013)\end{array}$ \\
\hline Finance & 0.126 & $\begin{array}{c}0.009 \\
(0.008)\end{array}$ & 0.143 & $\begin{array}{c}0.017 \\
(0.014)\end{array}$ & 0.100 & $\begin{array}{c}0.006 \\
(0.012)\end{array}$ \\
\hline Public administration & 0.115 & $\begin{array}{l}-0.029 \\
(0.008)\end{array}$ & 0.084 & $\begin{array}{l}-0.028 \\
(0.011)\end{array}$ & 0.148 & $\begin{array}{c}-0.028 \\
(0.015)\end{array}$ \\
\hline Construction & 0.075 & $\begin{array}{c}0.001 \\
(0.006)\end{array}$ & 0.081 & $\begin{array}{c}-0.011 \\
(0.011)\end{array}$ & 0.074 & $\begin{array}{c}0.005 \\
(0.010)\end{array}$ \\
\hline Manufacturing (non-metallic) & 0.069 & $\begin{array}{c}0.009 \\
(0.006)\end{array}$ & 0.089 & $\begin{array}{c}0.005 \\
(0.011)\end{array}$ & 0.058 & $\begin{array}{c}0.006 \\
(0.009)\end{array}$ \\
\hline Teaching & 0.064 & $\begin{array}{l}-0.002 \\
(0.006)\end{array}$ & 0.053 & $\begin{array}{l}-0.016 \\
(0.008)\end{array}$ & 0.076 & $\begin{array}{c}0.005 \\
(0.010)\end{array}$ \\
\hline Transport/storage/communication & 0.050 & $\begin{array}{c}0.005 \\
(0.005)\end{array}$ & 0.048 & $\begin{array}{c}0.003 \\
(0.008)\end{array}$ & 0.056 & $\begin{array}{c}0.000 \\
(0.009)\end{array}$ \\
\hline Manufacturing (metallic) & 0.039 & $\begin{array}{c}-0.002 \\
(0.004)\end{array}$ & 0.038 & $\begin{array}{c}0.004 \\
(0.008)\end{array}$ & 0.036 & $\begin{array}{c}-0.006 \\
(0.006)\end{array}$ \\
\hline Other community service & 0.037 & $\begin{array}{c}0.001 \\
(0.005)\end{array}$ & 0.032 & $\begin{array}{c}-0.003 \\
(0.007)\end{array}$ & 0.049 & $\begin{array}{c}-0.001 \\
(0.008)\end{array}$ \\
\hline Utilities & 0.027 & $\begin{array}{c}0.001 \\
(0.004)\end{array}$ & 0.027 & $\begin{array}{c}0.003 \\
(0.007)\end{array}$ & 0.028 & $\begin{array}{c}0.003 \\
(0.007)\end{array}$ \\
\hline Mining & 0.020 & $\begin{array}{c}0.007 \\
(0.004)\end{array}$ & 0.017 & $\begin{array}{c}0.009 \\
(0.006)\end{array}$ & 0.022 & $\begin{array}{c}0.007 \\
(0.006)\end{array}$ \\
\hline Agriculture & 0.018 & $\begin{array}{c}0.002 \\
(0.003)\end{array}$ & 0.027 & $\begin{array}{c}-0.005 \\
(0.006)\end{array}$ & 0.009 & $\begin{array}{c}0.007 \\
(0.004)\end{array}$ \\
\hline Social services and health & 0.018 & $\begin{array}{l}-0.003 \\
(0.003)\end{array}$ & 0.017 & $\begin{array}{c}-0.005 \\
(0.005)\end{array}$ & 0.020 & $\begin{array}{c}-0.002 \\
(0.006)\end{array}$ \\
\hline Index & 0.017 & $\begin{array}{c}0.001 \\
(0.000)\end{array}$ & 0.019 & $\begin{array}{c}0.002 \\
(0.001)\end{array}$ & 0.016 & $\begin{array}{c}0.001 \\
(0.001)\end{array}$ \\
\hline Have sector data & 0.711 & $\begin{array}{c}0.007 \\
(0.007)\end{array}$ & 0.730 & $\begin{array}{c}0.017 \\
(0.010)\end{array}$ & 0.707 & $\begin{array}{c}0.003 \\
(0.011)\end{array}$ \\
\hline $\mathrm{N}$ & & 36273 & & 13702 & & 14723 \\
\hline
\end{tabular}

Below-threshold probability and effect of elite admission on the probability of having main job in selected sectors from equation 2 (BW=10 specification, male student sample). 'All,' 'Private HS' and 'Non-private HS' headings denote sample populations. 'BL' column presents below-threshold baseline probability of working in listed sector (i.e., intercept in RD estimation equations). 'Effect' column presents point estimate of threshold-crossing effect. Standard errors in parentheses. 'Have sector' is an indicator equal to one if sector data is available for a student. N refer to counts of application-years with available sector data. Standard errors clustered at student level. Sectors sorted by baseline share in full sample. Sectors with less than $1 \%$ basline share omitted. 
Table 8: Effect of elite admission by below-threshold outcome

\begin{tabular}{lccc} 
& All & Private & Non-private \\
\hline A. Admissions effects by attribute & & & \\
Main effect & 0.097 & 0.166 & 0.092 \\
& $(0.072)$ & $(0.083)$ & $(0.118)$ \\
Peer score gap & -0.000 & -0.002 & 0.001 \\
& $(0.003)$ & $(0.003)$ & $(0.005)$ \\
Peer HS gap & 0.670 & 0.733 & 0.101 \\
& $(0.243)$ & $(0.278)$ & $(0.425)$ \\
Non-business fallback & 0.150 & 0.070 & 0.040 \\
& $(0.128)$ & $(0.153)$ & $(0.209)$ \\
Elite fallback & -0.277 & -0.318 & -0.429 \\
& $(0.118)$ & $(0.135)$ & $(0.208)$ \\
B. Split by tercile of private HS gap & & & \\
Top tercile & 0.156 & 0.180 & 0.063 \\
& $(0.069)$ & $(0.083)$ & $(0.116)$ \\
Middle tercile & 0.092 & 0.055 & 0.144 \\
& $(0.074)$ & $(0.088)$ & $(0.124)$ \\
Bottom tercile & -0.105 & -0.087 & -0.104 \\
& $(0.076)$ & $(0.084)$ & $(0.141)$ \\
N & 11866 & 7766 & 4100 \\
\hline
\end{tabular}

Standard errors in parentheses. Estimates of Equation 3 by HS type using 2000-2003 application data and the BW=20 specification in sample of male students. Dependent variable is log income. Panel A reports estimated main admissions effect and estimates of interactions between admission and the listed variables. 'Non-business fallback' is a dummy equal to one if a students' next-choice degree is not in business, law, or engineering. 'Peer score gap' is the difference between mean math scores at the target degree program and mean math scores at the next option. 'Private HS gap' is the difference between the fraction of students from private high schools at the target program and the fraction at the next option. Score gap and HS gap variables are demeaned (using means within the BW=20 sample). See Online Appendix E for descriptive statistics. 'Elite fallback' is a dummy variable equal to one if a students' next option is another elite degree program. Panel B reports estimates of equation 2 splitting by terciles of peer private HS gap. Sample pools over applications all elite degree programs, and excludes both admitted and rejected students who would not be admitted to any degree program if they were rejected from the target. 
Table 9: Graduation rates by student demographics and degree type

\begin{tabular}{lcccc} 
& \multicolumn{2}{c}{ Business } & \multicolumn{2}{c}{ Medical } \\
& Any & Target & Any & Target \\
\hline All & 0.796 & 0.695 & 0.947 & 0.911 \\
Male & 0.784 & 0.683 & 0.934 & 0.898 \\
Female & 0.827 & 0.725 & 0.965 & 0.929 \\
Gap (SE) & $-0.043,(0.008)$ & $-0.042,(0.009)$ & $-0.030,(0.011)$ & $-0.032,(0.014)$ \\
Within-program gap (SE) & $-0.053,(0.008)$ & $-0.060,(0.009)$ & $-0.034,(0.011)$ & $-0.036,(0.014)$ \\
N & \multicolumn{2}{c}{12294} & \multicolumn{2}{c}{1637} \\
Male private HS & \multicolumn{5}{c}{0.827} & 0.714 & 0.962 & 0.907 \\
Male non-private HS & 0.696 & 0.621 & 0.893 & 0.885 \\
Gap (SE) & $0.131,(0.010)$ & $0.093,(0.011)$ & $0.068,(0.019)$ & $0.022,(0.022)$ \\
Within-program gap (SE) & $0.110,(0.011)$ & $0.058,(0.012)$ & $0.067,(0.019)$ & $0.012,(0.023)$ \\
N & \multicolumn{2}{c}{8415} & \multicolumn{2}{c}{886} \\
\hline
\end{tabular}

Rows labeled 'All,' 'Male,' 'Female,' 'Private HS,' and 'Non-private HS' display mean rates of graduation for students of listed type. HS categories rows include only male students. 'Gap' rows are the gap between male and female graduation rates (upper row) and between private and non-private HS graduation rates (lower row). 'Within-program gap' rows are the difference in means by gender (upper row) or high school type (lower row) for students admitted to the same degree program. Columns: 'Business' columns includes sample of students admitted to elite business programs, 'Medical' columns are for sample of students admitted to elite medical degrees. Within each degree type, 'Any' records graduation rate within 10 years from any higher education institution, while 'Target' records graduation rates from the institution to which students are initially admitted. Data: 2000-2015 graduation data for admitted students in 2000-2005 cohorts. See section 5.5 for details. 
Table 10: Difference-in-difference estimates of peer effects on co-leadership

\begin{tabular}{lcccc} 
& $\begin{array}{c}\text { Private/ } \\
\text { Private }\end{array}$ & $\begin{array}{c}\text { Elite/ } \\
\text { Elite }\end{array}$ & $\begin{array}{c}\text { Private/ } \\
\text { Non-private }\end{array}$ & $\begin{array}{c}\text { Non-private/ } \\
\text { Non-private }\end{array}$ \\
\hline A.Single difference & & & & \\
Same cohort & 3.42 & 15.72 & 0.37 & 0.29 \\
& $(1.37)$ & $(9.17)$ & $(0.31)$ & $(0.30)$ \\
One year gap & 0.92 & 3.91 & 0.46 & 0.15 \\
& $(0.85)$ & $(5.09)$ & $(0.27)$ & $(0.20)$ \\
Two year gap & 0.94 & -0.33 & 0.24 & 0.16 \\
& $(0.76)$ & $(3.62)$ & $(0.20)$ & $(0.25)$ \\
Three year gap & 0.24 & 1.74 & 0.14 & -0.22 \\
& $(0.77)$ & $(5.58)$ & $(0.23)$ & $(0.07)$ \\
N & 5761326 & 658422 & 13119911 & 8207263 \\
B.Difference in differences & & & & \\
Same cohort & 3.64 & 20.93 & 0.58 & 0.56 \\
& $(1.67)$ & $(10.19)$ & $(0.56)$ & $(0.32)$ \\
One year gap & 0.19 & 5.58 & 0.54 & -0.02 \\
& $(1.20)$ & $(6.14)$ & $(0.39)$ & $(0.42)$ \\
Two year gap & -0.33 & 0.14 & 0.04 & -0.49 \\
& $(1.06)$ & $(4.20)$ & $(0.41)$ & $(0.48)$ \\
Three year gap & 1.51 & 6.43 & 0.44 & -0.19 \\
N & $(0.92)$ & $(6.48)$ & $(0.48)$ & $(0.22)$ \\
\hline
\end{tabular}

Standard errors in parentheses. Estimates of equations 4 and 5 by sample listed in column. 'Private/private' column consists of pairs of male private high school students. 'Elite/elite' column uses pairs of students where both members are from an elite private high school. 'Private/non-private' considers pairs where one student is from a private HS and the other is not. 'Non-private/non-private' is pairs of students both from non-private schools. Standard errors clustered use two-way clustering at the person-person level. 